\title{
Animal spirits and credit cycles
}

\author{
Paul De Grauwe ${ }^{\mathrm{a}, *}$, Corrado Macchiarelli ${ }^{\mathrm{a}, \mathrm{b}}$ \\ ${ }^{a}$ London School of Economics and Political Science, Houghton Street, London WC2A 2AE, United Kingdom \\ ${ }^{\mathrm{b}}$ Brunel University London, Kingston Lane, Uxbridge, Middlesex UB8 3PH, United Kingdom
}

\section{A R T I C L E I N F O}

\section{Article history:}

Received 3 April 2014

Received in revised form

3 July 2015

Accepted 13 July 2015

Available online 29 July 2015

\section{JEL Classifications:}

E03

E14

E44

\section{Keywords:}

Animal spirits

Credit cycle

Interest rate spread

Stabilization

\begin{abstract}
A B S T R A C T
In this paper we extend the behavioral macroeconomic model as proposed by De Grauwe (2012) to include a banking sector. The behavioral model takes the view that agents have limited cognitive abilities. As a result, it is "rational" to use simple forecasting rules and to subject the use of these rules to a fitness test. Agents are then driven to select the rule that performs best. The behavioral model produces endogenous and self-fulfilling movements of optimism and pessimism (animal spirits). Our main result is that the existence of banks intensifies these movements, creating a greater scope for booms and busts. Thus, banks do not create but amplify animal spirits. We find that increases in the equity ratios of banks tend to reduce the importance of animal spirits over the business cycle. The other policy conclusion we derive from our results is that the central bank has an important responsibility for stabilising output: output stabilization is an instrument to "tame the animal spirits". This has the effect of improving the trade-off between inflation and output volatility.
\end{abstract}

(c) 2015 The Authors. Published by Elsevier B.V. This is an open access article under the CC BY-NC-ND license (http://creativecommons.org/licenses/by-nc-nd/4.0/).

\section{Introduction}

Since the start of the financial crisis DSGE modelers have hurriedly attempted to introduce a banking sector into their models. This has been done in the framework of models that assume rational expectations, i.e. that assume that the representative agent understands the complexity of the underlying model. If there is anything we have learned from the financial crisis it is that this crisis was made possible by the fact that agents do not understand the complexity of the world in which they live. Instead, their cognitive abilities are very limited. Therefore there is a need to introduce a banking sector in models that recognize the cognitive limitations of agents. While recent contributions have explored the need to introduce banking in an agent based simulation framework (e.g., Ashraf et al., 2011; Delli Gatti et al., 2008), no attempts have been made to introduce bounded rationality and rule switching behaviour in a macro model that preserves the spirit of the original "financial accellerator approach" of Bernanke and Blinder (1988) and Bernanke et al. (1999). This is what we attempt to do in this paper.

Economists have long recognized the role of expectations' formation. This has been mainly in the light of evidence from experimental studies supporting the idea of information processing with agents' limited cognitive abilities. Recent contributions, including Carroll (2003), Mankiw et al. (2004), Branch (2004, 2007) and Pfajfar and Santoro (2010) provide empirical evidence in favor of agents' heterogeneity using survey data on inflation expectations. Honkapohja and Mitra (2005) point to the idea of agents possibly using structurally different learning rules. In the same vein, Frenkel and Froot

\footnotetext{
* Corresponding author.

E-mail address: P.C.De-Grauwe@lse.ac.uk (P. De Grauwe).
} 
(1987, 1990), Bloomfield and Hales (2002), Branch (2004), Hommes et al. (2005), Pfajfar and Zakelj (2011), Assenza et al. (2013), and Hommes (2011), find evidence in favor of heterogeneity in learning to forecast, conditional on recent forecasting performance, using both survey and laboratory data. Despite this evidence, the dynamic effects of expectations' heterogeneity has been explored only recently in macro models (for a survey, see Milani (2012)), and even less so in models with a banking sector (e.g., Ashraf et al., 2011; Delli Gatti et al., 2008).

Much of the previous attempts to model expectations that deviate from rational expectations have tried to stay as close as possible to the rational expectations' assumption. In these types of models, expectations of agents are assumed to satisfy a number of intuitive properties, including linearity and the law of iterated expectations (LIE). These include studies focusing on alternative forms of information processing, such as learning (Sargent, 1994; Evans and Honkapohja, 1999, 2001; Milani, 2007), rational inattention (Mackowiak and Wiederholt, 2005; Sims, 2003, 2005; Ball et al., 2005; Schorfheide, 2005); "sticky information" (Mankiw and Reis, 2002; Levine et al., 2012; Trabandt, 2007; Mankiw and Reis, 2007; Reis, 2009 in the DSGE literature) or bounded rationality at large (Sargent, 1994). All such models ask whether agents would converge to the same rational expectation equilibrium if they started with a more limited degree of knowledge or they were allowed to learn over time (for a discussion see Milani, 2012; Cornea et al., 2012; Massaro, 2013). ${ }^{1}$ These types of approaches generally produce sunspot-equilibria or multiple steady states (see Howitt and McAfee, 1992; Evans et al., 1998; and Evans and Honkapohja, 1999, 2001; Branch and Evans, 2007), overall improving the endogenous propagation of shocks, and hence model fit. Overall, however, as remarked previously, in the majority of cases such models have to tradeoff between rational and bounded-rational agents.

Following Brock and Hommes (1997, 1998), in this paper we treat the realization of economic choices as being an interactive process between different types of agents. In particular, following De Grauwe (2008a, 2008b, 2011, 2012), our model includes two types of agents. The first type are fundamentalists, who forecast output and inflation based on their equilibrium value. The second type use the simplest backward-looking rule of thumb - i.e., their forecast coincides with the last available observation - to forecast future the output gap and inflation. De Grauwe (2008a, 2008b, 2011, 2012) is not the only one to model heterogenous expectations in a New Keynesian Model (NKM). Recent examples of expectations' heterogeneity in a NK framework include Branch and McGough (2009) and Levine et al. (2012). In particular, Branch and McGough (2009) introduce heterogeneous expectations into a New Keynesian framework where the forward looking term in a New Keynesian Phillips Curve (NKPC) is a convex combination of backward- and forward-looking behaviors. The authors show that a microfounded NKM under bounded rationality can be obtained if specific axioms within the optimizing behavior of households and firms are considered, implying the law of iterated expactations (LIE). These axioms ensure the ability of agents to forecast the output gap and inflation at the micro level as well as aggregation at the macro level. Overall, however, such an approach, while making an important contribution to bridge aggregate forecasting rules with micro derivation, still strives to keep the benchmark rational expectations valid.

De Grauwe's approach is instead a more "radical" departure (Milani, 2007) from the previous literature (e.g. Branch and McGough, 2009), as no agent in the economy is assumed to have rational expectations. No agent in this economy posseses sufficient cognitive skills to understand the complexity of the underlying model and to know the distribution of the exogenous shocks hitting the economy. Rationality in this model is introduced instead by assuming agents are willing to learn from their mistakes. Thus, the concept of rationality used in De Grauwe (2008a, 2008b, 2011, 2012), and followed by this paper, is consistent with the idea that agents are aware of the fact that their beliefs are biased, but they are willing to learn from the past. In this set up, the heuristic behaviour employed in the formation of expectations is more "drastic" than the one employed by the standard bounded rationality literature in the sense that rational expectation equilibria are not nested by the model. ${ }^{2}$

We believe the assumption of individuals having cognitive limitations - leading them to use simple rules that do not take all the available information into account - is necessary once we take the view that agents are limited in their capacity to collect and process the immense information set that is present in the world. In our opinion, this evolutionary rationality is a better way to describe rationality in a world that is too complex and uncertain for agents to understand.

\section{The model}

In this section we first present the baseline behavioral macroeconomic model proposed by De Grauwe (2008a, 2008b, 2012). We then go a step further by decomposing aggregate demand into consumption and investment demand. Finally banks are introduced.

\footnotetext{
${ }^{1}$ Rationality would then not be achieved immediately either because of the existence of explicit costs in acquiring all information in the economy (i.e. full rationality implies agents already have full knowledge about the structure of the economy), or because agents are assumed to update their information only with some probability in each period.

2 The model presented in De Grauwe (2008a, 2008b, 2011, 2012) thus differs from multiple equilibria models in that it does not rely on extraneous "sunspots." The economic fluctuations are driven instead by the intrinsic random shocks of the model. This is similar to Evans and Honkapohja (2001, Ch. 14 ), but differ from the latter in that it does not have multiple equilibria under rational expectations.
} 


\subsection{The baseline behavioral macro model (BMM)}

Our baseline behavioral macroeconomic model (BMM) consists of three equations. An aggregate demand (AD) function:

$$
y_{t}=a_{1} \tilde{E}_{t} y_{t+1}+\left(1-a_{1}^{\prime}\right) y_{t-1}+a_{2}\left(r_{t}-\tilde{E}_{t} \pi_{t+1}\right)+\varepsilon_{t}, \quad\left(a_{2}<0\right)
$$

an aggregate supply (AS):

$$
\pi_{t}=b_{1} \tilde{E}_{t} \pi_{t+1}+\left(1-b_{1}\right) \pi_{t-1}+b_{2} y_{t}+\eta_{t},
$$

and a Taylor rule (TR):

$$
r_{t}=c_{1}\left(\pi_{t}-\pi_{t}^{*}\right)+c_{2} y_{t}+c_{3} r_{t-1}+u_{t} .
$$

In the equations above, $y_{t}$ is the output gap, $r_{t}$ the nominal interest rate, $\pi_{t}$ is inflation and $\varepsilon_{t}$ is a white noise disturbance term. Note that $\left(r_{t}-\tilde{E}_{t} \pi_{t+1}\right)$ is the real interest rate, where $\tilde{E}_{t}($.$) is the expectation operator, which is different from the$ standard "rational expectation" term where the representative consumer is assumed to forecast using all the information available. As explained in De Grauwe (2008a, 2008b, 2012), there is no direct derivation of the model at the microeconomic level, albeit Eqs. (1)-(3) are consistent with the log-linearized version of most New Keynesian models. The baseline model, based on Smets and Wouters (2007), shows how the AD is equivalent in fact to log-linearizing the Euler equation for consumer optimization, to which a smoothing term is added (see for instance Woodford, 2003). Given the sign restrictions posited, the aggregate demand equation has a very straightforward interpretation. Utility maximizing agents will want to spend more on goods and services today when they expect future income to increase, and to spend less when the real interest rate increases (De Grauwe, 2012).

Conversely, the aggreagate supply in Eq. (2) is the pure forward looking New Keynesian version of the AS based on Calvo-pricing (see for instance, Clarida et al., 1999; Woodford, 2003; De Grauwe, 2012) when $b_{1}=1$ (Branch and McGough, 2009). As before, this equation can be obtained by log-linearization around the steady state. With $0<b_{1}<1$ the relation incorporates an inertial term in the vein of Fuhrer and Moore (1995), Gali and Gertler (1999) and Woodford (2003).

Finally, the Taylor rule describes the behavior of the central bank, with $\pi_{t}^{*}$ being the inflation target. Based on TR, the central bank is assumed to raise the interest rate, $r_{t}$, when the observed inflation rate increases relative to the announced inflation target. The extent to which the central bank reacts to inflation depends on the coefficient $c_{1}$. Similarly, when the output gap increases, the central bank is assumed to raise the interest rate. The intensity with which it does so depends on the coefficient $c_{2}$. Finally, the central bank is assumed to smooth the interest rate. This smoothing behavior is represented by the lagged interest rate in Eq. (3).

Under rational expectations, the forward-looking terms, which are the expectations of the output gap and inflation respectively at time $t+1$ would be given by $\tilde{E}_{t} y_{t+1}=E_{t} y_{t+1}$ and $\tilde{E}_{t} \pi_{t+1}=E_{t} \pi_{t+1}$. As discussed before, in this paper we depart from rational expectations by considering instead the behaviorial approach of De Grauwe (2011, 2012). In this set up, expectations are a convex combination of the available heterogeneous expectation operators. The selection of the forecasting rules depends on the forecast performance of the different rules given by a publicly available fitness measure, which is updated in every period. For each variable we reduce the problem to a binary forecast choice (Brock and Hommes, 1997, 1998). After the equilibrium is revealed, forecasts are evaluated ex post according to the publicly available fitness measure and new fractions are determined. These updated fractions are used to determine the next period output gap and inflation and so on. Agents' rationality thus consists in choosing the predictor that performs better based on its past performance.

We now explain the selection mechanism in detail. Agents are supposed to forecast the output gap $(y)$ and inflation $(\pi)$ using two alternative forecasting rules. In the first one, (fundamentalist rule), agents are assumed to use the steady-state value of the output gap, $y^{*}$, here normalized to zero, to make a forecast. In the second one (called extrapolative rule), agents extrapolate the output gap's past observation. Analogously for inflation, agents are assumed to switch between a fundamentalist and an extrapolative rule. In an environment where the central bank explicitly announces its inflation target, inflation fundamentalists are assumed to base their expectations on the central bank's target, $\pi^{*}$. By contrast, inflation extrapolators behave exactly as output gap's extrapolators do: by naively forecasting inflation based - each time - on inflation's latest available observation.

Market forecasts of output gap and inflation are obtained as a weighted average of each respective forecasting rule (for each variable $y, \pi)$. In what follows we illustrate the behavioral rules for the output gap $(y)$. A similar notation can be used for inflation $(\pi)$. Convex combinations of the two forecasting rules are determined as

$$
\tilde{E}_{t} y_{t+1}=\alpha_{f, t} \tilde{E}_{t}^{f} y_{t+1}+\alpha_{e, t} \tilde{E}_{t}^{e} y_{t+1}
$$

where the fundamentalist rule $\tilde{E}_{t}^{f} y_{t+1}$ is defined as

$$
\tilde{E}_{t}^{f} y_{t+1}=y^{*}
$$

and the extrapolative $\tilde{E}_{t}^{e} y_{t+1}$ rule is

$$
\tilde{E}_{t}^{e} y_{t+1}=\theta y_{t-1} \text {. }
$$

The latter is a form of adaptive or extrapolative expectations. Adaptive expectations of this kind have been used by Brock and Hommes (1997, 1998), Branch (2002), Branch and McGough (2009), and Pesaran (1987). When $\theta=1$ the operator is usually called 
"naïve". For $\theta<1$ expectations are instead adaptive, whereas for $\theta>1$ expectations are said to be "extrapolative" (see Brock and Hommes, 1998). To keep the model tractable, in the paper we assume $\theta=1$, but refer to the latter as an extrapolative rule.

In the model, we focus on the cyclical component of each variable, which makes the model symmetric with respect to zero (see, e.g., Harvey and Jaeger, 1993). ${ }^{3}$ In this environment, the equilibrium forecast for each variable will be constant over time and equal to each variable's steady-state value. This is realistic in a stationary world, where, for instance, an inflation target of, e.g., zero would imply the central bank seeks to minimize deviations of the (realized) target rate of inflation from the corresponding time-varying equilibrium (steady-state) value. The same reasoning applies to output in deviation from its potential (i.e. the output gap).

In Eq. (4), the weights attached to each forecasting rule ( $\alpha_{f, t}$ for the fundamentalist rule and $\alpha_{e, t}$ for the extrapolative rule) vary endogenously within the model. The reason for having different forecasting rules is supported by the empirical literature. For instance, Frankel and Froot (1990) find that professional market participants in the foreign exchange markets expect recent price changes to continue in the short term, while they expect mean reversion to the fundamental (steady state) value over the long term. Regarding the use of extrapolative rules, backward-looking forecasting strategies, although extremely simple, may be useful particularly when the underlying stochastic process is a random walk. For instance, for a persistent process like inflation (or its gap) (see Cogley (2002), Cogley and Sargent (2007)), naive expectations can be a good predictor at times (see Cornea et al. (2012), De Grauwe (2012) and Roos and Schmidt (2012)).

We base our forecasting rule mechanism on a dynamic predictor selection, in line with discrete choice theory. This mechanism allows switching between the two forecasting rules by computing the utility of the two rules and increase (decrease) the relative weight of one rule against the other in each period. Under the formalization that the utilities of the two alternative rules have a deterministic and a random component - and assuming the latter to be logistically distributed (see Manski and McFadden, 1981; Anderson et al., 1992) - the weights in Eq. (4) can be defined based on each period utility (U.,t, see also De Grauwe (2012)).

For the output gap, the corresponding weights take the form

$$
\alpha_{f, t}^{y}=\frac{\exp \left(\gamma U_{f, t}^{y}\right)}{\exp \left(\gamma U_{f, t}^{y}\right)+\exp \left(\gamma U_{e, t}^{y}\right)}
$$

and

$$
\alpha_{e, t}^{y}=1-\alpha_{f, t}^{y}=\frac{\exp \left(\gamma U_{e, t}^{y}\right)}{\exp \left(\gamma U_{f, t}^{y}\right)+\exp \left(\gamma U_{e, t}^{y}\right)},
$$

where each rule's utility is determined by

$$
U_{f, t}^{y}=-\sum_{k=0}^{\infty} w_{k}\left[y_{t-k-1}-\tilde{E}_{t-k-2}^{f} y_{t-k-1}\right]^{2}
$$

and

$$
U_{e, t}^{y}=-\sum_{k=0}^{\infty} w_{k}\left[y_{t-k-1}-\tilde{E}_{t-k-2}^{e} y_{t-k-1}\right]^{2}
$$

In the expression above, $w_{k}=\left(p^{k}(1-p)\right.$ ) are geometrically declining weights (with $1 \leq p \leq 0$ ), allowing to take into account the degree of forgetfulness in the model (see De Grauwe (2012)). The parameter $\gamma$ measures the "intensity of choice". It parameterizes the extent to which the deterministic component of utility determines actual choice. When $\gamma=0$ utility is purely stochastic. In that case agents decide to be fundamentalist or extrapolator by tossing a coin and the probability to be one or the other is exactly 0.5 . When $\gamma=\infty$ utility is fully deterministic and the probability of using one rule or the other is either 1 or 0 . The parameter $\gamma$ can also be interpreted as expressing the willingness to learn from past performance. When $\gamma=0$ this willingness is zero; it increases with the size of $\gamma$.

From the utility maximization problem, it is clear that most agents will tend to choose the predictor that yielded higher utility over the past. Agents are thus "boundedly" rational in the sense that they use simple rules but subject these rules to a "fitness test". The extent to which agents switch between rules depends on how well a given rule performs ex post relative to the other. In this sense agents learn from their mistakes.

Importantly, this mechanism allows endogenizing the evolution of the distribution of heterogeneous agents, with this proportion $\left(\alpha_{t}\right)$ being estimated at each time. ${ }^{4}$ This is different from other approaches, e.g., Branch and McGough (2009), where weights are not endogenously esitmated by the model. As underlined by Cornea et al. (2012) the empirical evidence does support the idea of changing the proportion of heterogeneous agents over time. Carroll (2003) and Mankiw et al.

\footnotetext{
${ }^{3}$ For this reason, a non-negative interest rate constraint is not applied in the model: a negative interest rate in this economy should be understood as a negative interest rate gap (i.e. the interest rate in deviation from the natural rate of interest). Based on the model parameters, it is possible to infer the unconditional probability of a negative real interest rate gap (that is when expected inflation gap is higher than the nominal interest rate in deviation from the natural rate of interest). In line with standard predictions, a negative real interest rate stimulates the economy, i.e. the output gap will be positively affected.

${ }^{4}$ While the ex-ante the probability of using each forecasting rule for each variable is 0.50 , ex post this probability may vary. Matching those probabilities with empirical evidence from survey data is on our research agenda, but, for the moment, it remains beyond the scope of this analysis.
} 
(2004), for instance, show that the distribution of heterogenous agents varies in reaction to economic volatility, whereas, Castle et al. (2010) test for multiple structural breaks in inflation expectations in a NK Phillips curve framework.

\subsection{Decomposing the aggregate demand}

The aggregate demand described previously can be decomposed into consumption $(c)$ and investment $(i)$ sides of the economy:

$$
y_{t}=c_{t}+i_{t} .
$$

We specify the consumption and investment equations, respectively, as follows:

$$
\begin{aligned}
& c_{t}=d_{1} y_{t}+d_{2} \tilde{E}_{t} y_{t+1}+\left(1-d_{1}-d_{2}\right) y_{t-1}+d_{3}\left(r_{t}-\tilde{E}_{t} \pi_{t+1}\right)+v_{t}^{c}, \quad\left(d_{3}<0\right) \\
& i_{t}=e_{1} \tilde{E}_{t} y_{t+1}+e_{2}\left(r_{t}-\tilde{E}_{t} \pi_{t+1}\right)+v_{t}^{i} . \quad\left(e_{2}<0\right)
\end{aligned}
$$

According to Eq. $\left(1^{\prime}\right)$, output $y_{t}$ is absorbed by consumption or investment. Public expenditure and taxation are absent in the model which ensures that income and output correspond in the consumption and investment equations.

Consumption, $c$, depends on three factors. First, on current income, according to the parameter $d_{1}$ which represents the marginal propensity of consumption. Second, it depends on the expected future output gap, $\tilde{E}_{t} y_{t+1}$. The latter term is equivalent to considering an exogenous level of private consumption even at level zero of income. Third, consumption depends on past income, introducing a habit formation mechanism which is assumed to slow down the adjustment of consumption to its optimal level after a shock (see also De Grauwe (2008a, 2008b, 2012), Smets and Wouters (2007)). Finally, consumption depends negatively on the ex ante real interest rate $\left(r_{t}-\tilde{E}_{t} \pi_{t+1}\right)$, for $d_{3}<0$.

Following a standard approach, investment depends first on a forward looking component, the expected future output gap, $\tilde{E}_{t} y_{t+1}$. Second, it negatively depends on the real interest rate, according to the parameter $e_{2}<0$, which measures the sensitivity of investment to changes in the ex ante real interest rate.

Substituting (5) and (6) into (1') and comparing it with (1) yields the following cross-parameter restrictions: $a_{1}=\left(d_{2}+e_{1}\right) /$ $\left(1-d_{1}\right), a_{1}^{\prime}=\left(d_{2}\right) /\left(1-d_{1}\right), a_{2}=\left(d_{3}+e_{2}\right) /\left(1-d_{1}\right)$ (with $\left.0<d_{1}<1\right)$ and $v^{c}{ }_{t}+v^{i}{ }_{t}=\varepsilon_{t}$.

\subsection{Introducing banks}

Banks are implicitly included in this model, since the interest rate is the price of credit. However, in order to account for banks explicitly, we introduce financial intermediaries which are assumed to collect money from savers (consumers) and lend it to borrowers (firms). The balance sheet of commercial banks accounts for loan supply $\left(L^{S}\right)$, on the asset side, and deposits $(D)$, on the liability side. Banks' equity $\left(n^{b}\right)$ serves as an important cushion against unexpected losses. It is defined as the difference between assets and liabilities:

$$
L_{t}^{S}=n_{t}^{b}+D_{t}
$$

For a commercial bank, the leverage is thus the ratio between its loans and equity. In this respect, banks are subject to an explicit capital-to-asset ratio, i.e.

$$
\frac{n_{t}^{b}}{L_{t}^{S}}=\kappa,
$$

with $\kappa$ being the equity ratio (the inverse of banks' leverage ratio). When a firm borrows money from a bank, it must pay an interest which normally exceeds the interest rates that savers receive for deposits. Hence, the cost of a loan from banks, $\rho$, is usually equal to the rate savers receive (here equal to the risk-free rate set by the central bank, $r$ ) plus a spread, $x$.

$$
\rho_{t}=r_{t}+x_{t}
$$

The investment demand in Eq. (6) is hence replaced with Eq. (6'), assuming investment to depend on the cost of bank loans, as

$$
i=e_{1} \tilde{E}_{t} y_{t+1}+e_{2}\left(\rho_{t}-\tilde{E}_{t} \pi_{t+1}\right) . \quad\left(e_{2}<0\right)
$$

In this way, the spread is assumed to affect the overall investment decisions of firms directly.

Incorporating banks into the aggregate demand - by means of Eqs. (1'), (5), (9) and (6') - gives:

$$
y_{t}=a_{1} \tilde{E}_{t} y_{t+1}+\left(1-a_{1}^{\prime}\right) y_{t-1}+a_{2}\left(r_{t}-\tilde{E}_{t} \pi_{t+1}\right)+\left(a_{2}+a_{3}\right) x_{t}+\varepsilon_{t}, \quad\left(\left(a_{2}+a_{3}\right)<0\right)
$$

where $a_{1}$ and $a_{2}$ are defined as before and $a_{3}=-d_{3} /\left(1-d_{1}\right)$. This new aggregate demand function in (1") subsitutes the one in (1) or (1'), where banks are absent. Comparisons of Eqs. (1) and (1") suggest that - while the aggregate demand still depends on future expected and past income and (negatively) on the real interest rate - it also depends on the spread, $x_{t}$. Since the slope coefficient $\left(a_{2}+a_{3}\right)$ is negative for $0<d_{1}<1$ and $e_{2}<0$, i.e. $a_{2}+a_{3}=e_{2} /\left(1-d_{1}\right)$, this new aggregate demand represents a negative relationship between $y$ and $x$. 
Bank lending further implies (stocks of) consumers' savings to flow into deposits according to

$$
D_{t}-D_{t-1}=s_{t} \text {. }
$$

In the same vein, loan demand $\left(L^{D}\right)$ and investment are related by

$$
L_{t}^{D}-L_{t-1}^{D}=i_{t},
$$

Thus we assume that savings take the form of an accumulation of bank deposits, and investments by firms are financed by bank loans only.

Saving, $s$, is finally determined as

$$
s_{t}=y_{t}-c_{t}-v_{t}
$$

as in the standard IS-LM set up.

The next step in the analysis is to determine what the spread between the borrowing and the deposit rate is. We use the financial accelerator model of Bernanke, Gertler and Gilchrist (1999). Defining $n^{f}$ as firms' equity, we write

$$
x_{t}=\rho_{t}-r_{t}=\varphi n_{t}^{f}, \quad(\varphi<0)
$$

An increase in the firms' equity reduces the spread and viceversa. The underlying financial accelerator theory is the following. Banks have imperfect knowledge of the credit risk they take when granting a loan to a firm. To cover this credit risk they charge a spread $\left(x_{t}\right)$. When the value of equity of the firm increases this is interpreted by the bank as an improvement in the solvency of the firm. Thus, banks will perceive the credit risk to have declined allowing them to reduce the spread. A decline in the value of the firms equity has the opposite effect. Such a decline is interpreted as reducing the solvency of the firm and increasing the credit risk. Banks react by raising the spread.

A firm with more debt than equity is leveraged. We define the leverage ratio, $\tau$, as

$$
\tau=\frac{L_{t}^{D}}{n_{t}^{f}}
$$

To keep the model simple, it will be assumed here that firms keep the leverage ratio constant. According to Eq. (14), this implies that as the loan demand increases the firm will issue more equity in the same proportion (in Section 6 we will make firms' leverage ratio endogenous).

By putting together Eqs. (11) and (14), one realizes that the equity of firms depends on the inverse of firms' leverage ratio $(\tau)$, which is the equity ratio, as

$$
n_{f}^{t}=\frac{1}{\tau}\left(L_{t-1}^{D}+i_{t}\right)
$$

e.g., Bernanke et al. (1999).

The spread clears the lending market determining the total level of loanable funds to firms. Here, loan demand $\left(L^{D}\right)$ is a function of investment, $L_{t}^{D}=L^{D}(i)$. Via Eq. (7) loan supply $\left(L^{S}\right)$ is a function of banks' equity and deposits, i.e. $L_{t}^{S}=L^{S}\left(n^{b}, D\right)$, where bank equity is simply the difference between loans and deposits (subject to the contraint in Eq. (8)). Via the banks' balance sheet the market is cleared for $L^{S}=L^{D}$.

\section{Solving the model}

We obtain a model with five endogenous variables, the output gap, inflation, the borrowing-lending spread, savings and the interest rate. The first four are obtained after solving the following set of equations:

$$
\begin{aligned}
& {\left[\begin{array}{llll}
1 & -b_{2} & 0 & 0 \\
-a_{2} c_{1} & 1-a_{2} c_{2} & -\left(a_{2}+a_{3}\right) & 0 \\
-\varphi \tau^{-1} e_{2} c_{1} & -\varphi \tau^{-1} e_{2} c_{2} & \left(1-\varphi \tau^{-1} e_{2}\right) & 0 \\
d_{3} c_{1} & -\left(1-d_{1}-d_{3} c_{2}\right) & 0 & 1
\end{array}\right]\left[\begin{array}{l}
\pi_{t} \\
y_{t} \\
x_{t} \\
s_{t}
\end{array}\right]}
\end{aligned}
$$

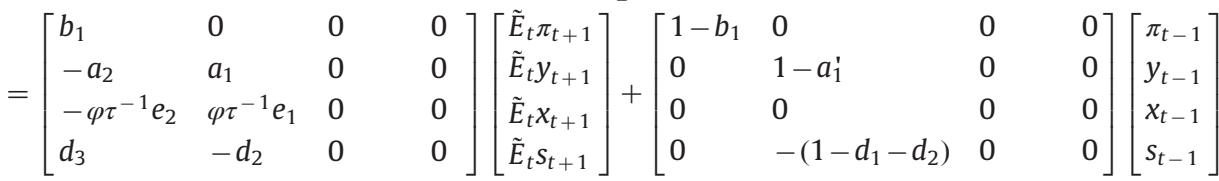

$$
\begin{aligned}
& +\left[\begin{array}{lll}
0 & 0 & 0 \\
a_{2} c_{3} & 0 & 0 \\
\varphi \tau^{-1} e_{2} c_{3} & \varphi \tau^{-1} & \varphi \tau^{-1} \\
d_{3} c_{3} & 0 & 0
\end{array}\right]\left[\begin{array}{l}
r_{t-1} \\
D_{t-1} \\
n_{t-1}^{b}
\end{array}\right]+\left[\begin{array}{ccc}
1 & 0 & 0 \\
0 & a_{2} & 1 \\
0 & \varphi^{-1} \tau e_{2} & 0 \\
0 & -d_{3} & -\left(1-d_{1}\right)
\end{array}\right]\left[\begin{array}{l}
\eta_{t} \\
u_{t} \\
\epsilon_{t}
\end{array}\right]
\end{aligned}
$$

In compact form, this is written as $\mathbf{A Z} \mathbf{Z}_{\mathbf{t}}=\mathbf{B} \tilde{\mathbf{E}}_{\mathbf{t}} \mathbf{Z}_{\mathbf{t}+1}+\mathbf{C Z}_{\mathbf{t}-1}+\mathbf{D} \mathbf{X}_{\mathbf{t}-1}+\mathbf{E} \mathbf{v}_{\mathbf{t}}$. As in De Grauwe (2008a, 2008b, 2011, 2012), a solution for $\mathbf{Z}_{\mathbf{t}}$ is obtained as $\mathbf{Z}_{\mathbf{t}}=\mathbf{A}^{-1}\left(\mathbf{B} \tilde{\mathbf{E}}_{\mathbf{t}} \mathbf{Z}_{\mathbf{t}+1}+\mathbf{C} \mathbf{Z}_{\mathbf{t}-1}+\mathbf{D} \mathbf{X}_{\mathbf{t}-1}+\mathbf{E} \mathbf{v}_{\mathbf{t}}\right)$ with the only condition being $\mathbf{A}$ to be non-singular. 
Some comments are warranted in the next section. We obtain the value of the interest rate recursively by substituting output gap and inflation into the Taylor rule. Investments, equities and deposits are determined by the model solutions for inflation, the output gap, the spread and savings. ${ }^{5}$

\subsection{Model solution under rational expectations vs. "heuristics"}

The expectational term with a tilde superscript in the system of equations above implies that we do not impose rational expectations. By substitutitng the law of motion consistent with the heterogeneity of agents (extrapolators and fundamentalists discussed before), it can be shown that the endogenous variables depend linearly on lagged endogenous variables, their equilibrium forecasts, the usual predetermined variables and current exogenous shocks. In reduced form, the model is written as:

$$
\mathbf{A Z}=\mathbf{F Z}+\mathbf{G Z}_{\mathbf{t}-1}+\mathbf{D X} \mathbf{X}_{\mathbf{t}-1}+\mathbf{E v}_{\mathbf{t}}
$$

where $\overline{\mathbf{Z}}$ is a vector of constants, $\mathbf{F}=\mathbf{B H}, \mathbf{G}=\mathbf{B}[\mathbf{I}-\mathbf{H}]+\mathbf{C}$, and $\mathbf{H}$ is a diagonal matrix, where the weights attached to each variable's fundamentalist rule are on the main diagonal.

In other words, under consideration of the heuristics for the forecasts regarding the output and inflation expectations, the forward looking term in Eqs. (2), (3), (5) and (6) is substituted by the equivalent expressions for the discrete choice mechanism given in Section 2.1. It can be gauged indeed that the model becomes purely backward-looking and it can be solved iteratively.

In a standard rational expectation environment, the vector of variables multiplied by $\mathbf{F}$ would typically be $\mathbf{E}_{\mathbf{t}} \mathbf{X}_{\mathbf{t}+1}$ instead, thus bringing the problem to the same level of a rational expectations' problem with predetermined variables. In the latter case, defining $\mathbf{M}$ as

$$
\mathbf{M}=\left[\begin{array}{cc}
\mathbf{F}^{-1} \mathbf{A} & -\mathbf{F}^{-1} \mathbf{G} \\
\mathbf{I}_{2} & 0
\end{array}\right]
$$

implies the model solution would require having to deal with determinacy, depending on the magnitude of the eigenvalues of $\mathbf{M}$ and the number of predetermined variables (see Blanchard and Khan (1980)). ${ }^{6}$

Other than fully-departing from rational expectations, the specification adopted in this paper is indeed different from that of, e.g. Branch and McGough (2009), where a fraction of agents is rational (forward-looking) and the remainder is adaptive (backward-looking); or that of Cornea et al. (2012), which differ from the former in that it allows forward-looking agents not to have model-consistent expectations (rational) but to forcast according to a VAR present value model à la Campbell and Shiller (1987). In both cases, however, rational expectation represents the limiting case. ${ }^{7}$

From a modeling point of view, keeping the rational expectation benchmark is not without difficulties. As underlined by Milani (2012) and De Grauwe (2011, 2012) in the benchmark New Keynesian model under rational expectations, the model fails to match the persistence of macroeconomic time-series. As a result, such a model is normally extended to include, in addition to several highly-autocorrelated exogenous shocks, other sources of endogenous inertia, such as habit formation, interest rate smoothing, sticky prices etc. (for a discussion see Milani (2012)). In Section 8, we empirically discuss some of those issues.

\section{Calibration}

For the aggregate demand function we calibrate the parameters $\left(d_{1}, d_{2}, e_{1}\right)$ to match standard macroeconomic simulation results, broadly consistent with De Grauwe $(2011,2012)$. This is to ensure comparability with the baseline macroeconomic model without a credit sector. A Table of coefficient is provided in Appendix A. Overall, however, the parameters are calibrated consistent with the intervening literature. The new banking sector parameters are calibrated as follows: $d_{1}$ is computed to match a marginal propensity to consume (MPC) out of income equal to 0.5 , in line with the empirical literature pointing to a MPC in the range of 0.2-0.7 (Friedman, 1963; Carroll, 2012; Iacoviello and Neri, 2010). The remaining parameters are derived consistently with the sign restrictions posited, namely a firms' leverage factor of $\tau=1.43$, following Pesaran and Xu (2013) and $\varphi<0$. For the

\footnotetext{
5 The spread and saving need not to be forecasted, as their forecasts do not enter the model. This does not affect the dynamics of the model (i.e. there is no structure of higher order beliefs in our framework; see Section 3.1).

${ }^{6}$ See also Binder and Pesaran (1996) and Evans and McGough (2005).

7 With respect to our approach, a methodological issue clearly arises. The forecasting rules (heuristics) introduced here are not derived at the micro level and then aggregated. Instead, they are imposed ex post. As stressed in De Grauwe (2011), however, this has also been the approach in the learning literature pioneered by Evans and Honkapohja (2001). Ideally, one would like to derive the heuristics from the micro-level in an environment in which agents experience cognitive problems. Branch and McGough (2009) propose an approach where a given number of axioms are needed for aggregation. In particular, the axioms imposed in Branch and McGough impose regularity on the expectation operator and facilitate aggregation. As Branch and McGough emphasizes, their axioms restrict agents' expectations so that they satisfy the LIE at both an individual and aggregate level. The LIE at the individual level is a reasonable assumption as it implies agents' information set is constant over time. As the authors underline, however, the assumption of LIE at the aggregate level requires a particular structure on higher-order beliefs, which may be a too restrictive assumption in the presence of unanticipated structural breaks shifting or even changing the underlying distribution of e.g., output gap and inflation (see, e.g., Hendry and Mizon, 2010). We thus do not make such an assumption here.
} 
latter, corresponding estimates are not available with precision in the literature. ${ }^{8}$ Thus, we calibrate $\varphi$ so that the spread displays the desirable propery of being always positive, and consistent with the historical average of the bank prime lending rate vs. 6-month Treasury bill spread, as in Bernanke, Gertler and Gilchrist (1999), corresponding to an average of about 250 basis points (see Fig. 1). Banks' equity ratio (the inverse of the leverage ratio, $k$ ) is set equal to 0.09 , consistent with the target parametrization in Gerali et al. (2010) and pretty much in line with the recent regulatory capital requirements for commercial banks. ${ }^{9}$

The parameters that govern the selection mechanism across rules are calibrated as in De Grauwe (2011), again to ensure comparability (see Appendix A), which is $\gamma=1$ and $p=0.5$. De Grauwe (2011) also explores the sensitivity of the results by varying different key parameters in the switching mechanism, including the degree of forgetfullness in the model $(p)$ or the intensity of choice parameters in the Brock-Hommes function $(\gamma)$. His results, showing that numerical results are attained across different parameterization of the model, remain valid for our model as well. ${ }^{10}$

\section{Results}

\subsection{Animal spirits drive the business cycles}

Figs. 2 and 3 show the time pattern of output gap and animal spirits produced by the baseline model with banks in a typical simulation run. We observe a strong cyclical movement in the output gap (Fig. 2). The source of these cyclical movements is seen to be the index of animal spirits in the market (Fig. 3). We define animal spirits as the fraction of agents who forecast a positive output gap. When this fraction is 1 all agents forecast such a positive output gap, i.e. they are all optimistic. When the fraction is zero all agents forecast a negative output gap; they are all pessimistic. The model creates endogenous waves of optimism and pessimism. These are highly correlated with movements in the output gap (0.91) (see also De Grauwe (2008a, 2008b, 2011, 2012)). During some periods, pessimism dominates and this translates into below average output growth. These pessimistic periods are followed by optimistic periods when optimistic forecasts tend to dominate, with above average growth.

In Fig. 4 we present the frequency distribution of the output gap. It turns out that this distribution is not normal. It has fat tails (i.e. kurtosis is 3.84 and normality is rejected with $p$-value 0.000 based on the Jarque-Bera test). Note that the stochastic shocks in the model are all i.i.d. thus the non-normality of the distribution of the output gap is generated by the model. This contrasts with standard linear DSGE models that are only able to produce non-normal movements in output by introducing non-normally distributed shocks (see also Section 8). The mechanism in our model that produces the non-normality is the interaction between animal spirits and output. As more and more agents become, say, optimists, they forecast positive output gaps. These forecasts are self-fulfilling and produce a boom, which tends to accelerate as more agents become optimists. The reverse happens when the downturn sets in.

We obtain more insight in this mechanism by plotting the frequency distribution of animal spirits in Fig. 5 . The latter is just a representation of the same animal spirits of Fig. 3, but in the frequency domain. We observe that there is a concentration of observations at the extreme values of +1 (everybody is optimist) and 0 (everybody is pessimist). Thus, the dynamics of animal spirits are characterized by movements in optimism and pessimism, leading to "market frenzy" and large movements in economic activity.

Fig. 6 shows the evolution of the spread in the time domain. The spread is negatively correlated with animal spirits $(-0.087)$. The reason is that during an upturn of economic activity when agents are optimistic, the value of equity of firms increases, leading banks to lower the spread. The opposite occurs during a downturn. The correlation coefficient is low, however, suggesting that this effect is weak. The relatively low correlation coefficient has much to do with the fact that the banks cannot easily expand their balance having to obey to the balance sheet contraint in Eq. (7), and being subject to an explicit capital requirement as set in Eq. (8), in every period.

To study the implications of changing regulatory capital requirements, we further vary the equity ratio $k$ (or, the inverse of banks' leverage ratio) in the interval [0.0,0.18] and simulate the model over this range of different $\mathrm{ks}{ }^{11}$ From Fig. 7 we observe that, as banks increase their equity ratio, the correlation between animal spirits and output gap does not decline significantly. This suggests that by raising the equity ratio of banks the authorities cannot significantly reduce the scope for animals spirits to lead to boom and busts in economic activity in this model. In a later section we discuss ways to make the banks' balance sheets react to the state of the economy.

\subsection{Banks amplify animal spirits}

A key ingredient in our model is a pro-cyclical boom-bust cycle in credit, following a tightening or loosening of credit conditions. This amplifies waves of optimism and pessimism, which are themselves self-fulfilling, sowing the seeds of business cycles phases (Section 2.3).

\footnotetext{
${ }^{8}$ For a discussion on steady state estimates for the spread see also Mehra, Piguillem and Prescott (2008), Curdia and Woodford (2010).

${ }^{9}$ Note that the (risk weighted) capital ratio in Basel III, comprising common equity and a capital conservation buffer, is equal to $7 \%$. Basel III also assumes the possibility of a countercyclical buffer, which is imposed within a range of $0-2.5 \%$, bringing the common equity standard to an interval of 7 9.5\% (Basel Committee on Banking Supervision, 2011). In section 6, we perform a sensitivity analysis by looking at the robustness of our results by varying banks' optimal equity ratio in the interval $0-18 \%$.

${ }^{10}$ These results are available upon request from the authors.

11 The model varies $k$ in steps of 0.03 . For values larger than 0.96 (i.e. $k=0.99$ ) the model becomes explosive.
} 


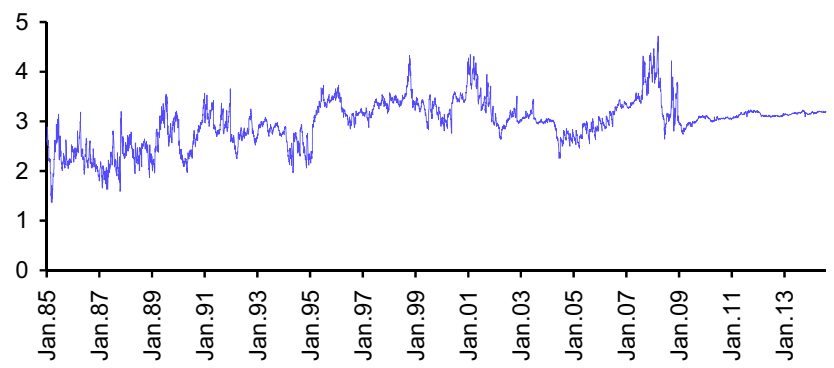

Fig. 1. Bank prime loan rate vs. 6-month Treasury bill.

Source: Federal Reserve Bank of Saint-Louis Economic Data (FRED).

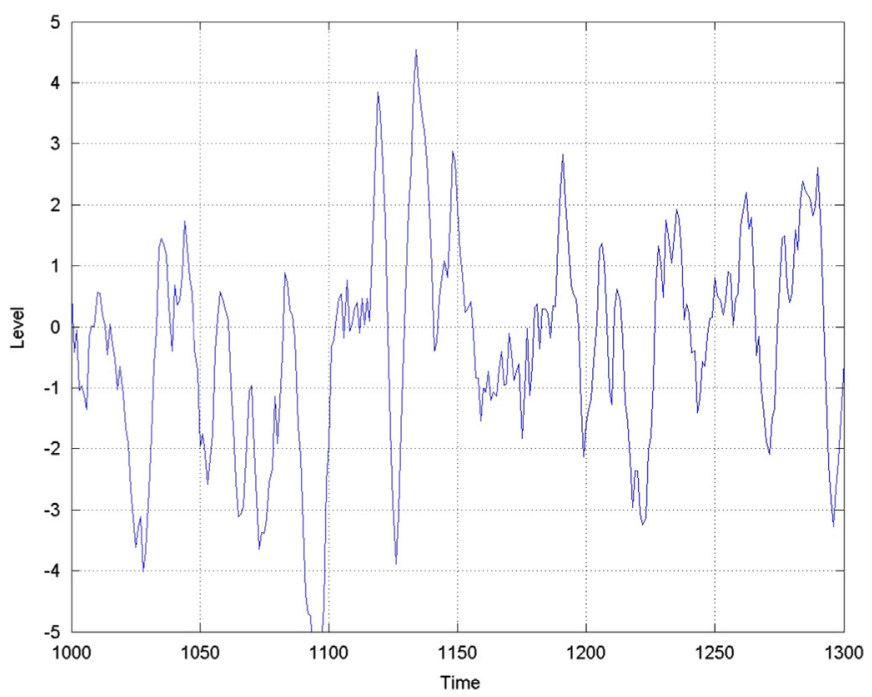

Fig. 2. Output gap.

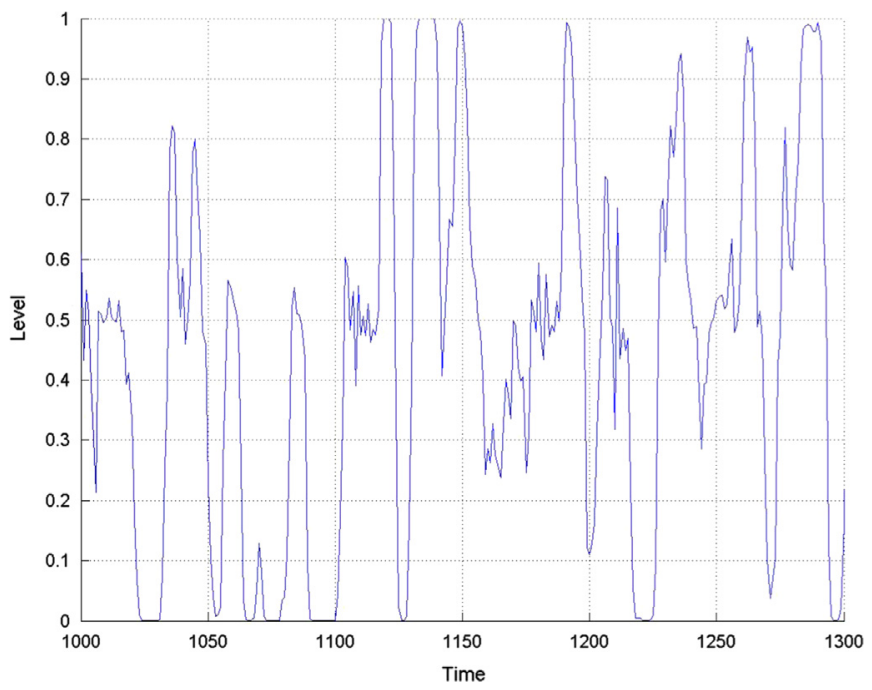

Fig. 3. Animal spirits.

In this section we switch "on and off" the banking sector. This allows us to check the extent to which banks amplify animal spirits. We do this by varying the parameter $\varphi$. The latter is a key parameter in the model: in fact, for $\varphi=0$ there is no spread in the economy (i.e. borrowers and lenders will face the same risk free interest rate). This corresponds to the case where there is no banking sector. As $\varphi$ increases (in absolute value), banks become more active and allow the spread to vary as a function of the firms' equity. 


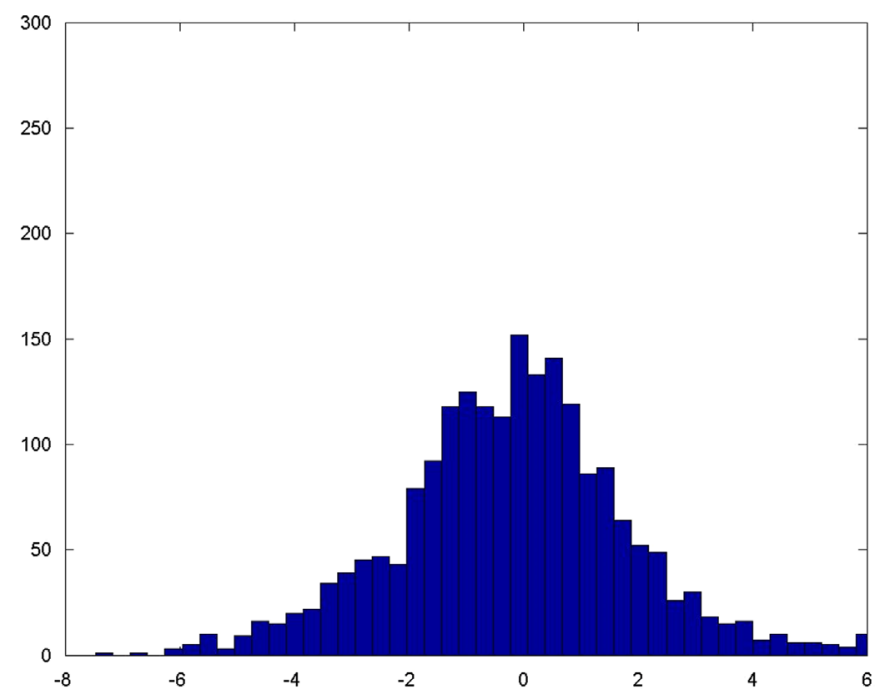

Fig. 4. Histogram output gap.

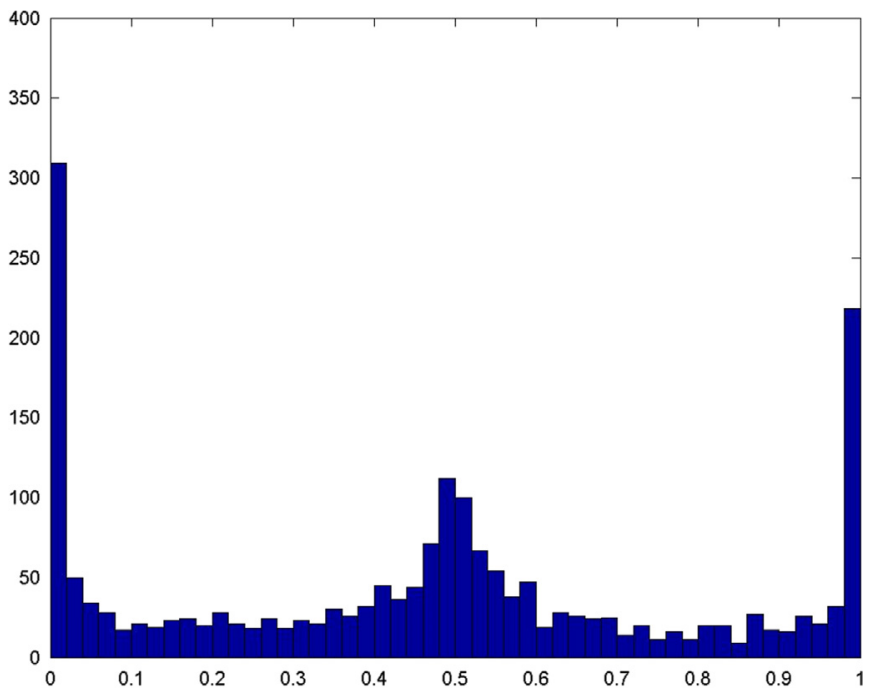

Fig. 5. Histogram animal spirits.

We vary $\varphi$ in the interval 0 (i.e. no banking sector) to -0.2 to explore how the banks amplify the animal spirits. We report the pattern of animal spirits for different values of $\varphi$ in Fig. 8. The different lines in the graph are not explained by changes in the firms' collateral value, but by the varying presence of banks in the model. This is indeed distinct from the leverage cycle literature (see also Section 6), which points out the amplifying effect of the interplay of the constraints faced by borrowers and lenders.

We can see from Fig. 8 that when banks are not present $\varphi=0$, tail events (periods during which everyone is pessimist or optimist) are less likely. As soon as $\varphi$ increases in absolute value, correlations in beliefs become more and more likely. Once again, this is only explained by varying the presence of banks in the model.

Fig. 9 looks at the distribution of animal spirits in the frequency domain (the scale is the same through the different panels in Fig. 9). Using different values of $\varphi$, Fig. 9 confirms how banks themselves amplify animal spirits. As $\varphi$ increases we obtain a larger concentration of extreme optimism and pessimism.

\subsection{Effects of monetary policy shocks}

In this section, we analyse the impulse responses following an unanticipated increase in the interest rate. In Fig. 10, the monetary policy shock occurs after 100 periods in the simulations to reduce the effect of starting values. The impulse 


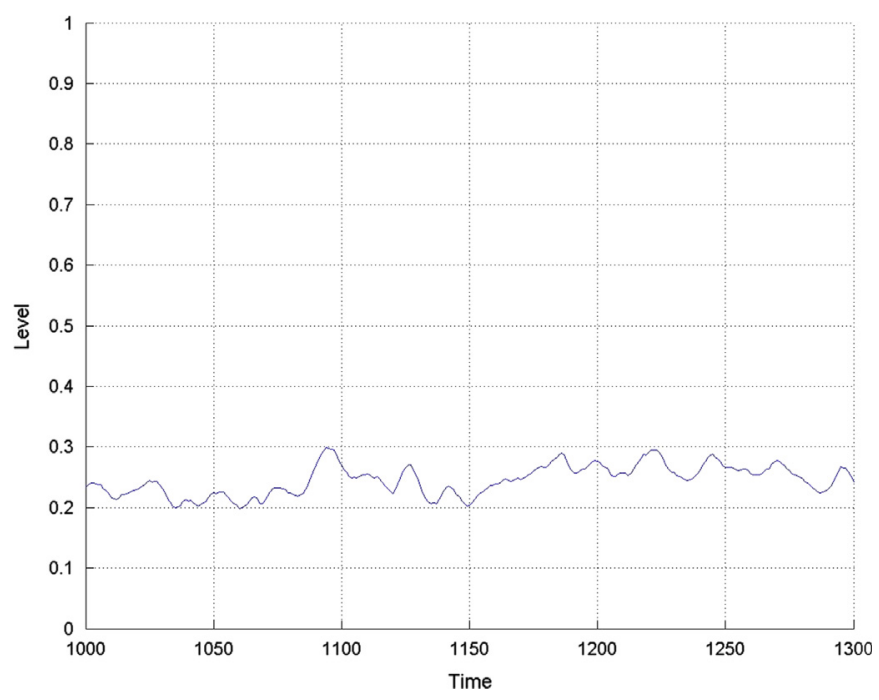

Fig. 6. Borrowing-lending spread.

responses to a temporary i.i.d. monetary policy shock are reported for output (impulse $y$ ), inflation (impulse p), investment (impulse $i$ ) and the spread (impulse $x$ ).

We obtain the traditional results, i.e. output, investment and inflation decline following monetary policy tightening. The results also confirm the pro-cyclicality of credit. The interest rate induced decline in output and investment has the effect of reducing the equity of firms. As a result, their creditworthiness declines. This then induces banks to raise the spread. Thus, this effect is pro-cyclical, i.e. it tends to enhance the downturn initiated by the central bank's increase in its interest rate.

At this point the question would be: how much of these dynamics are explained by animal spirits? The mechanism described previously suggests that animal spirits make agents react to the state of the economy. Looking again at the IRFs, we evaluate how the model reacts to a monetary policy shock allowing for learning or not in the economy. Based on the model, allowing agents to learn in real time creates endogenous correlation in beliefs, hence animal spirits, as opposed to the case where agents are not allowed to learn.

We carry out this exercise in two ways. We first simulate the model with a probability of shifting to each forecasting rule equal to 0.5 . As discussed previously, fixing the probability at $50 \%$ corresponds to the case where agents toss a coin (or $\gamma=0$ in the Brock-Hommes' function; see Section 2.1). Hence, there is no scope for animal spirits in the model, as the selection of the forecast rules in the model becomes completely stochastic.

As an alternative parametrization, we use the ex post probabiliy of shifting among forecasting rules. This involves simulating the model in two steps. First we simulate the standard model without restrictions. In a second step, we take the the ex post probability, i.e. the probability observed after a simulation run, and use it to run the model a second time (step two). Importantly, in this way the probability of being fundamentalist or extrapolator is indeed fixed, but different from 0.5 (i.e. in this case it will be $\alpha_{f, t}^{y}=0.76$ and $\left.\alpha_{f, t}^{p}=0.57\right) .^{12}$ Using a fixed probabily clearly reduces the correlation between output and animal spirits. In case a $50 \%$ probability is used, no animal spirits are allowed in the model. Hence, the correlation between output and animal spirits is virtually zero ( -0.001$)$. Using the probability ex post, the correlation between output and animal spirits drops to 0.72 .

For the sake of brevity, we report the impulse responses to a temporary i.i.d. monetary policy shock for output (e.g. impulse $y$ ) and inflation (e.g. impulse $p$ ) given the discussion above. The results of the standard model with heuristics (Fig. 11, blue line) display a larger reaction compared to the case where the probability of switching between forecasting rules is fixed. Not allowing agents to learn dampens animal spirits. This is very much the case when we use a $50 \%$ probability (impulse y5). Using the probability ex post represents an intermediate step (impulse ypost), laying in between one extreme, where agents learn over time, and the other extreme, where the probability of using one rule against the other remains set at 50\%, i.e. corresponding to agents tossing a coin. These results overall make clear how animal spirits actually play a crucial role in generating some of the key findings (e.g. in terms of model persistency and volatility) in this model.

\section{Leverage and stock prices}

\subsection{The extended bank model}

In the previous sections we discussed how the balance sheet constraint implied banks could not lend more than they borrowed from households. Banks had no alternatives other than reduce credit availability during a boom, and viceversa. This pretty much fixed their balance sheets over the business cycle.

\footnotetext{
${ }^{12}$ However measured, using a fixed probability makes the pattern of animal spirits become discrete.
} 


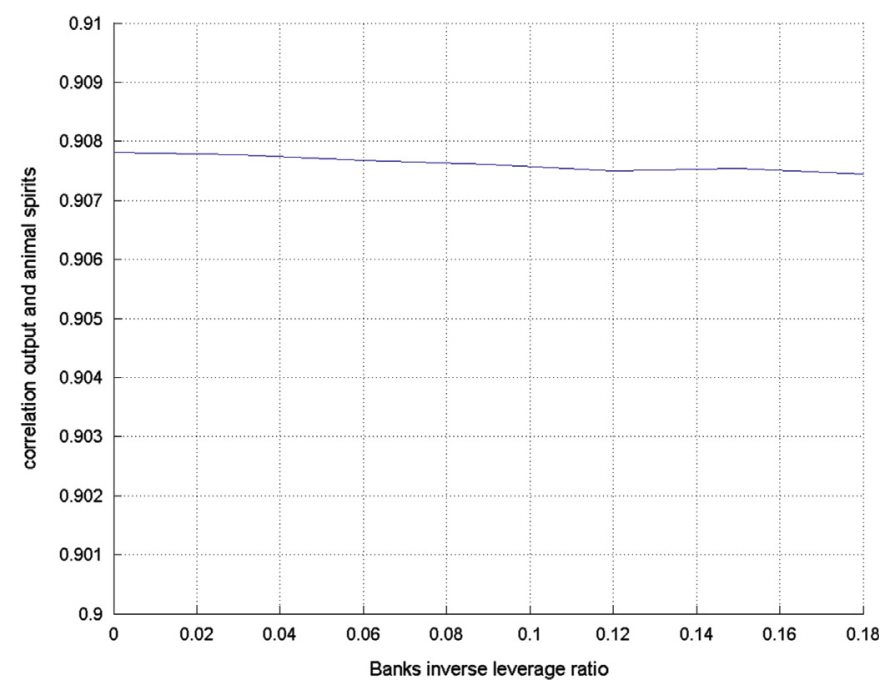

Fig. 7. Correlation output and animal spirits vs. banks' capital requirement.

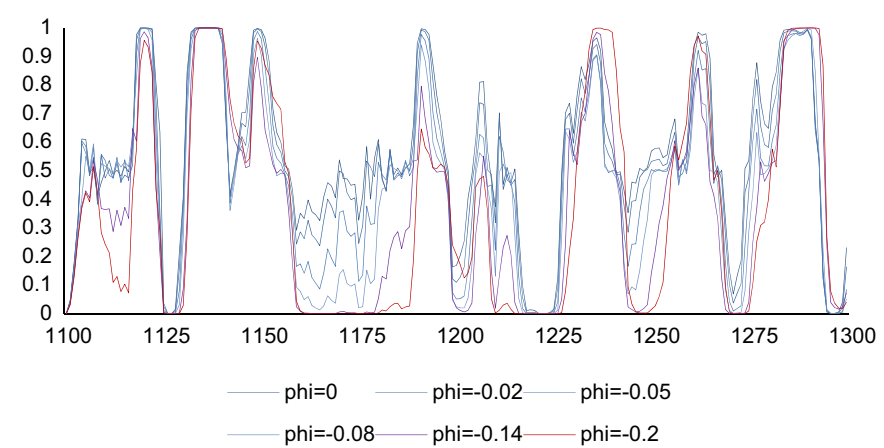

Fig. 8. Animal spirits for different values of $\varphi \mathrm{s}$. (For interpretation of the references to color in this figure, the reader is referred to the web version of this article.)

In practice, however, there exist mechanisms that can lead banks to expand their balance sheets during booms and contract them during recessions, thereby amplifying business cycle movements. In this section we analyze one such mechanism. It will be based on the link between the firms' asset values and the banks' balance sheets and it is related to what the literature refers to as the leverage cycle (see Geanakoplos $(1997,2009)$ ). The leverage cycle normally requires that firms post collateral with the bank, and the bank has a balance sheet item called "posted collateral". When, during a boom the asset prices of good firms go up (equity increases), the firm's collateral constraint relaxes and its creditworthiness improves. During a downturn asset prices decline, and the firm's collateral constraint becomes more biting (for further discussion see Geanakoplos (1997, 2009), Brunnermeier and Pedersen (2009), Adrian and Shin (2010)). Based on such a leverage cycle, an amplification effect exists when incentives for both banks and firms to bear risk related to the provision of loans are affected. Essentially, a boost in asset and collateral values (together with the belief that the increase in asset values is sustainable; ECB, 2011; Mankiw and Ball, 2010) may lead both borrowers and firms to accept higher risk (i.e. "risk taking channel"), resulting in an excessive loan provision. This mechanism may easily come into play if admitting banks hold risky assets on their balance sheets, e.g. firms' shares, and following a positive reevaluation of the profitability of these assets.

In order to have asset price variability to contribute to the volatility in firms' equity, we resort to the idea that firms' market capitalization is equal to the number of (time-varying) shares $\left(\bar{n}_{t}\right)$ multiplied by the current share price $\left(S_{t}\right)$, i.e.

$$
n_{t}^{f, m}=\bar{n}_{t} S_{t} .
$$

To derive share prices, we use the standard Gordon discounted dividend model, ${ }^{13}$

$$
S_{t}=\frac{E_{t} \bar{\Lambda}_{t+1}}{R_{t}^{S}}
$$

\footnotetext{
${ }^{13}$ See e.g., Brealey and Myers (1984).
} 
a

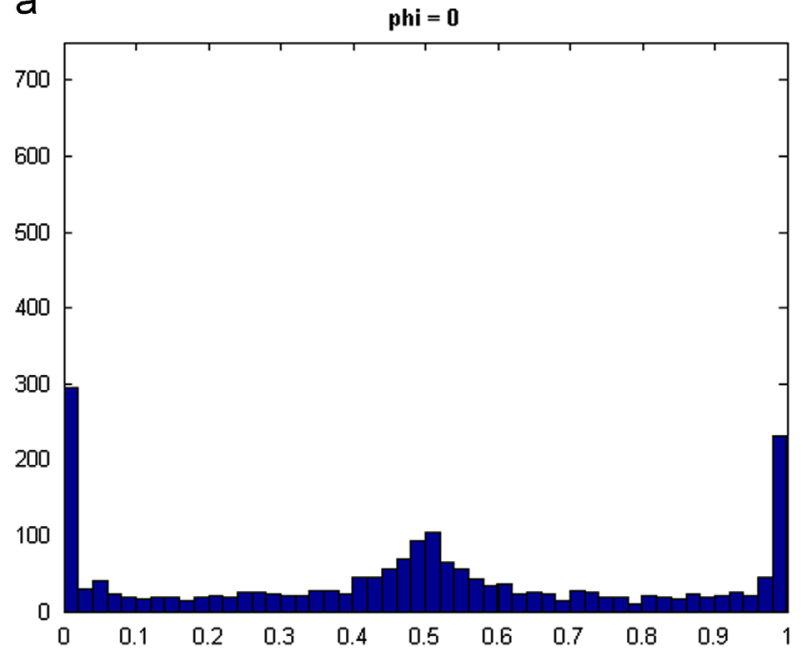

C

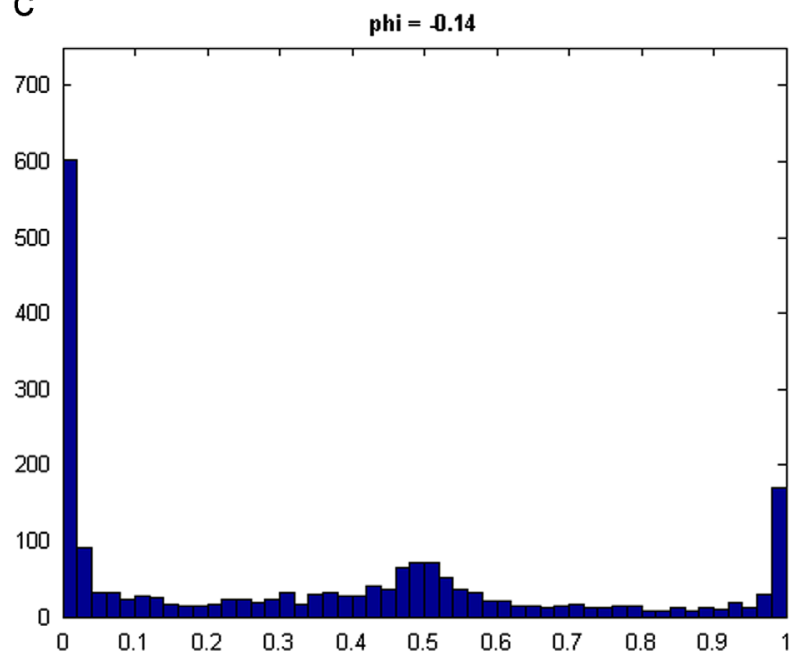

b

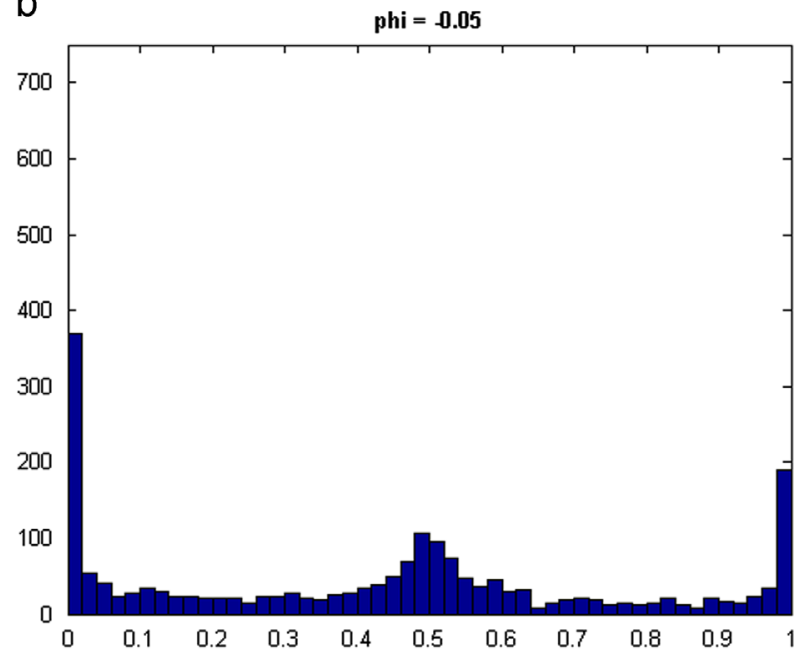

d

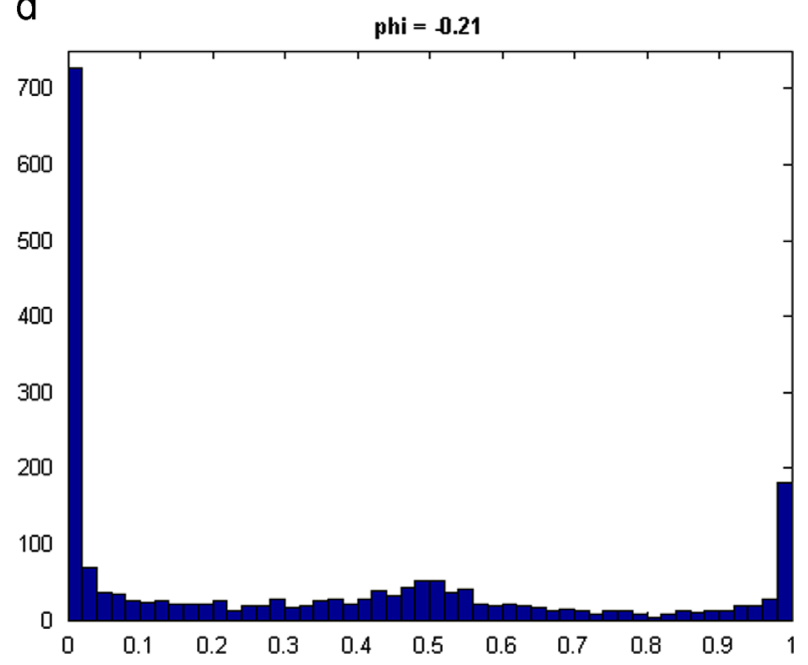

Fig. 9. Histogram of animal spirits for different values of $\varphi$ s.

with

$$
R_{t}^{S}=r_{t}+\xi
$$

linking the asset price $S_{t}$ to expected future dividends $\left(E_{t} \bar{\Lambda}_{t+1}\right)$ net of a discount rate $R_{t}$. The latter consists of the risk-free interest rate plus a constant equity premium $(\xi)$. We calibrate $\xi$ to be $5 \%$, which is in line with the historical average market risk premium.

The standard stable growth (Gordon) model assumes that dividends grow at a constant rate. The forecasts made by agents about future dividends follows the logic of the forecasts they make for the output gap. Agents assume the 1-period ahead forecast of dividends to be a fraction of nominal GDP one period ahead, whereas dividends are assumed to be constant thereafter (from $t+1$ onwards). This forecast is reevaluated in every period. Since nominal GDP consists of a real and an inflation component, agents make a forecast of future output gap and inflation, in the same way as analyzed in Section 2. Thus, the forecasts are reevaluated in each period, and agents are willing to switch to another forecasting rule if this performs better than the one they currently use.

As before (Eq. (13)), we assume that the spread is determined by the value of the firms' equity. We substitute (15) into (13) to obtain (see also Bernanke and Gertler (2001)).

$$
x_{t}=\varphi \bar{n}_{t} S_{t}, \quad(\varphi<0)
$$



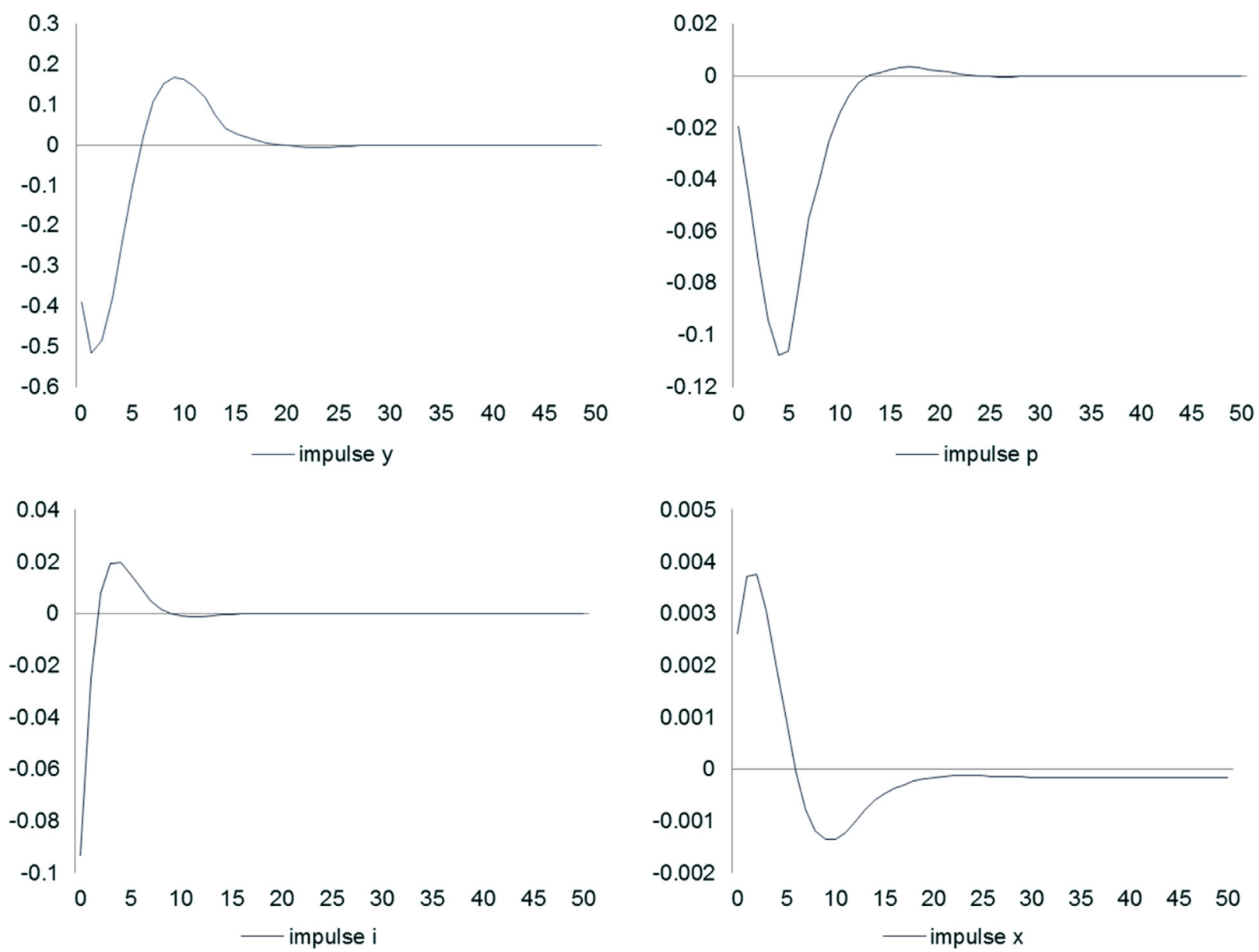

Fig. 10. IRFs to monetary policy shock.
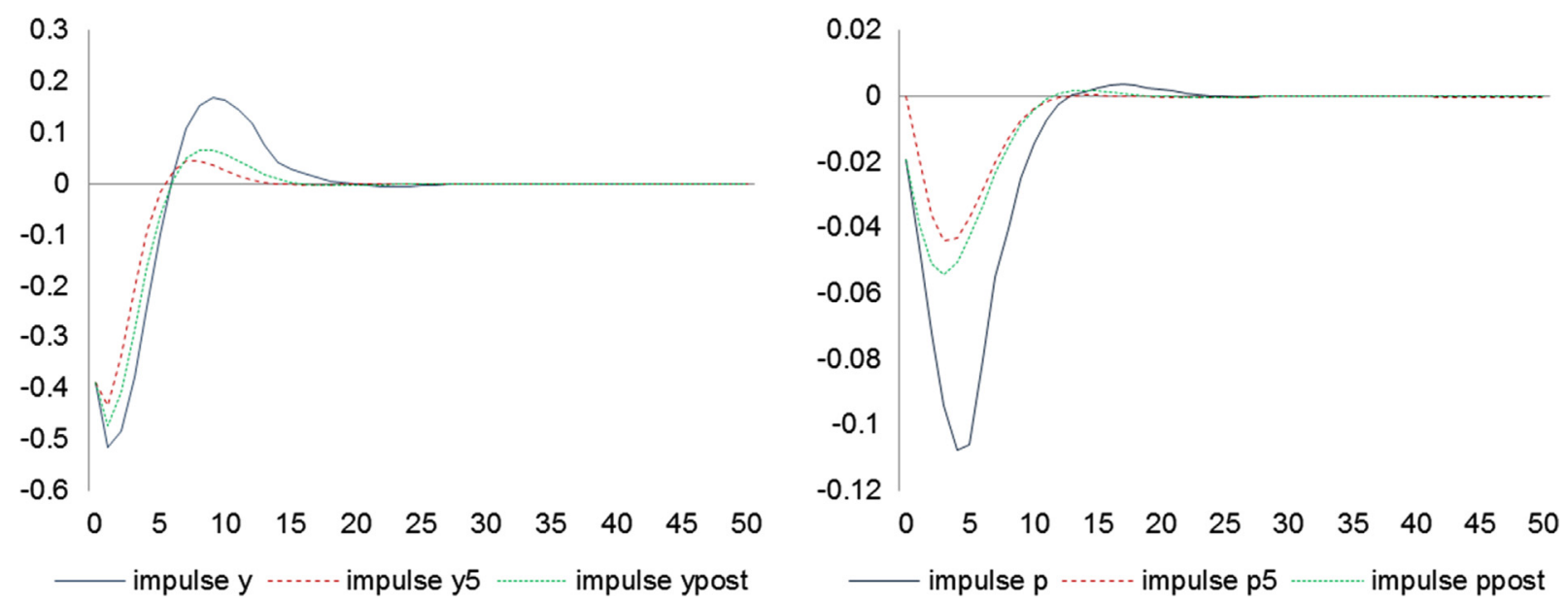

Fig. 11. IRFs to monetary policy shock with and without learning. (For interpretation of the references to color in this figure, the reader is referred to the web version of this article.)

As a result, share prices, by affecting the firms' financial positions, influence the spread. Given these additional dynamics in $S$, firms' leverage in Eq. (14) is no longer exogenous. It is defined by the new Eq. (14')

$$
\tau_{t}=\frac{L_{t}^{D}}{\bar{n}_{t} S_{t}}
$$


Finally, the bank's balance sheet is modified in a way that allows for asset prices to feed back on the bank's balance sheet. In particular, it is assumed that banks own a fixed fraction, $\overline{\bar{n}}$, of firms' shares. ${ }^{14}$

\begin{tabular}{ll}
\hline Tot. Assets $(A)$ & Liabilities $(B)$ \\
Loans $\left(L^{S}\right)$ & Deposits $(D)$ \\
Risky assets $(\overline{\bar{n}} S)$ & Own equity $\left(n^{b}\right)$ \\
\hline
\end{tabular}

In this way, the sum of total assets, $A_{t}$, to be considered in the banks' balance sheet identity is simply:

$$
A_{t}=L_{t}^{S}+\overline{\bar{n}} S_{t}
$$

and the new balance sheet constraint of the banks is given by the following:

$$
A_{t}=n_{t}^{b}+D_{t}
$$

substituting Eq. (7).

The link between asset prices and the banks' balance sheets can now be described as follows. An increase in asset prices increases the available collateral, leading to a decrease in leverage on the part of the borrowers, and granting potential access to credit. Financial intermediaries, in turn, see the value of their assets increase and will then have incentives to expand lending. This then tends to bring down the spread. Thus, asset prices affect the aggregate demand (investment) via credit spread dynamics. ${ }^{15}$

\subsection{Results with the extended banking model}

We simulated the extended model using the same calibration as in the simple model. The results of the simulations are shown in Figs. 12-16.

A comparison with the simulations obtained with the simple model of Section 2 leads to a number of interesting insights. First, in the extended model with endogenous asset prices we obtain longer waves of optimism and pessimism leading to larger movements in the output gap, compared to the model without endogenous asset prices. This can be seen from the time series results of the output gap and animal spirits in Figs. 12 and 13 compared to Figs. 2 and 4 (note the different scales in Figs. 12 and 13). The frequency distribution of the output gap exhibits fatter tails in the banking model with asset prices. Analogously, animal spirits and their frequency distribution (Figs. 14 and 15) display more concentration of observations in the extremes of optimism and pessimism in the new model with endogenous asset prices.

To study the implications of changing regulatory capital requirements with the extended model, we again vary the equity ratio $k$ in the interval [0.0,0.18], as described previously. When asset prices are included (Fig. 17), the policy implications of varying banks' capital requirements become much clearer. Importantly, the correlation between animal spirits and output gap is now downward sloping with increasing values of $k$. This is consistent with the "risk taking channel" idea. Thus, tightening banks' capital requirements reduces the scope for banks to take risks, alleviating the effect of animal spirits over the business cycle. In particular, for $k=0.15$ the animal spirits vs. output's correlation drop to nearly 0.1 , compared to the case where $k$ is $9 \%$. This suggests that the equity ratio is of use as a policy intrument when asset prices are included in the model. ${ }^{16}$

\section{Monetary policy implications}

The existence of endogenous movements in optimism and pessimism (animal spirits) has important implications for monetary policy. The way we analyze these implications is by constructing tradeoffs between output and inflation variability. In standard DSGE-models these tradeoffs are always downward sloping. This means that in these models, any attempt to reduce output volatility by the use of the interest rate instrument comes at a price, i.e. more inflation volatility. Put differently, if the monetary authorities decide to increase their ambition to stabilize output fluctuations, they may be succesful in reducing output volatility, but this will be achieved by increasing inflation volatility.

In our behavioral model we obtain a different result. In order to show this point we construct the tradeoffs between output and inflation volatility using the behavioral model with the simple banking sector. We do this by varying the output coefficient in the Taylor rule equation, $c_{2}$, from 0 to 1 (keeping the inflation coefficient constant). For each value of $c_{2}$ we simulate the model and compute the standard deviations of output and inflation. We plot these numbers in a figure with the

\footnotetext{
${ }^{14}$ Banks hold only a fixed fraction of firms' shares, as making banks hold firms completely would otherwise erode incentives for banks to charge an excess premium over firms' lending.

15 This is different from De Grauwe (2008a, 2012, Chapter 7), where asset prices enter the aggregate demand directly. See also Case et al. (2003).

16 The extended banking model allows for an extra pass through from animal spirits to the banks' balance sheet. By increasing banks' leverage ratio we are simply reducing this pass-through forcing banks' to take less risk. If we dampen animal spirits, for instance assuming agents toss a coin (i.e. the probability of using one forecasting rule or the other is fixed at 50\%), the correlation between output and animal spirits would be virtually 0 most of the time (see Figs. A1 and A2 in Appendix A) with no scope for tightening banks' capital requirements.
} 


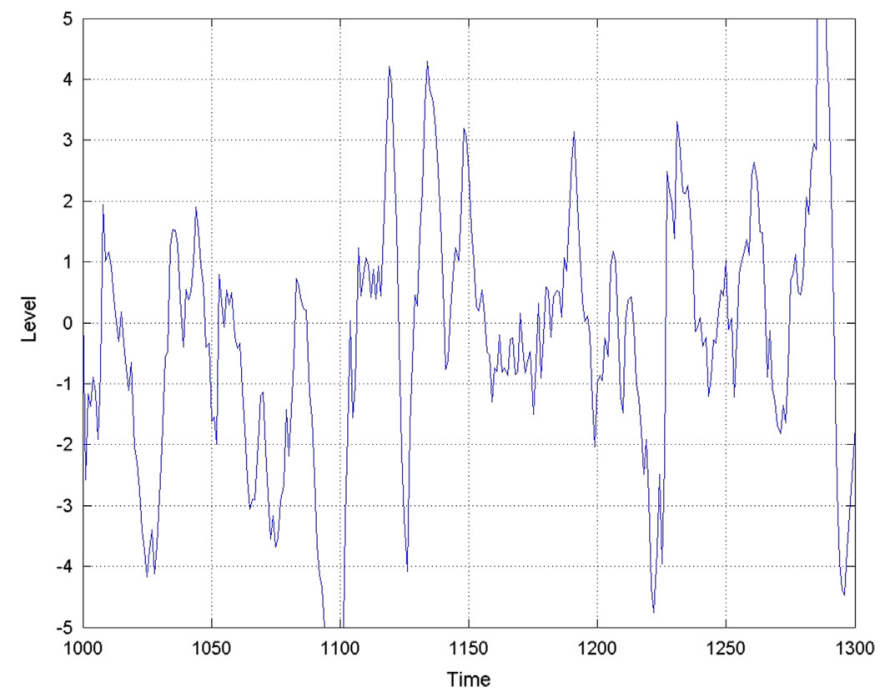

Fig. 12. Output gap.

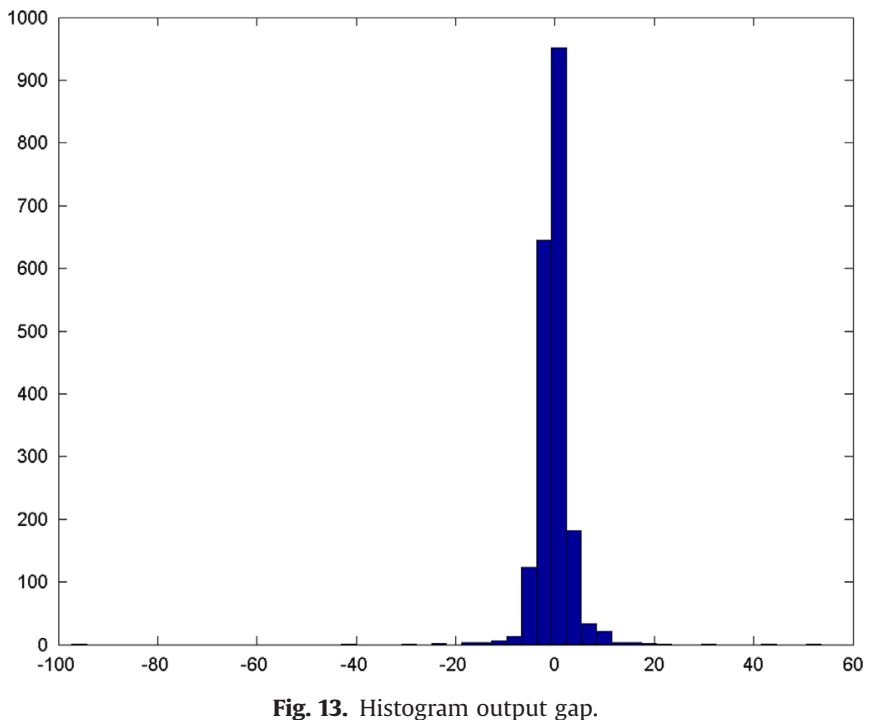

standard deviation of inflation on the vertical axis and the standard deviation of output on the horizontal axis. We repeat this exercise for different inflation coefficients, so as to obtain one trade-off for every given inflation coefficient. The results are reported in Fig. 18.

The striking aspect of our results is that the tradeoffs we obtain are non-linear in nature. In order to understand the nature of this non-linear trade-off we start from point $\mathrm{A}$ on the tradeoff obtained when $c_{1}=1$. Point $\mathrm{A}$ corresponds to the situation where the central bank sets $c_{2}=0$, i.e. it does not attempt to stabilize output at all. If the central bank then starts increasing $c_{2}$, we go down the tradeoff. This means that, for a given $c_{1}$, increasing the output stabilization parameter reduces both output volatility (not surprising) and inflation volatility (surprising). Where does this effect come from? The answer is that by stabilizing output, the central bank helps in stabilizing animal spirits (waves of optimism and pessimism). The latter is a source of volatility not only of output but also of inflation. By "taming the animal spirits" the central bank reduces both inflation and output volatility. It follows that strict inflation targeting can never be optimal.

There are limits to this "win-win" situation, however. The central bank can overdo its output stabilization effort. This is achieved where the tradeoff reaches the minimum point and becomes a negatively sloped line. We reach this point because too much output stabilization undermines the credibility of the inflation target.

Inflation targeting remains important. We observe from Fig. 18 that, by increasing $c_{1}$, the tradeoff moves downwards. This means that, as the central bank follows a tighter inflation targeting policy rule, the tradeoffs improve. They remain nonlinear though, which means that even in tighter inflation targeting regimes it pays to stabilize output. 


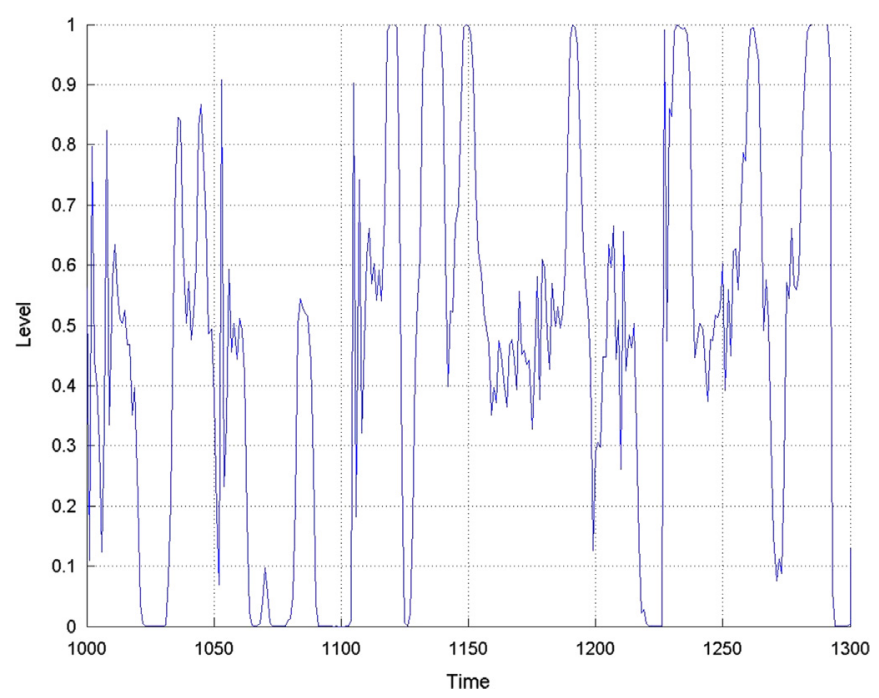

Fig. 14. Animal spirits.

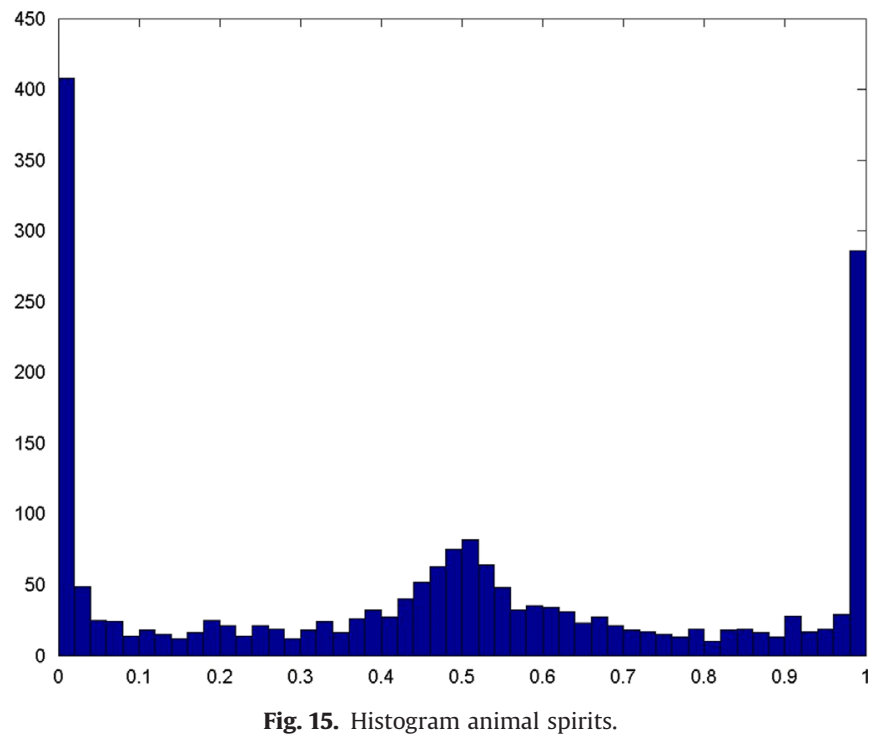

\section{Empirical issues}

In this section, we contrast the dynamics of a standard NK model both with heuristics and under rational expectations. For the sake of clarity, we focus on the case in which $\varphi=0$, implying no asymmetry of information between lenders and borrowers, thus the standard three equation NK model. We further impose the following set of restrictions on the model parameters: $b_{1}=1$ (implying no backward looking term in the AS), $c_{3}=0$ (implying no interest rate smoothing) and $\left(d_{1}+d_{2}\right)=1$ (implying no habit in consumption, and hence in the AD function). The motivation for doing so is to show how the performance of a parsimonious model varies when assuming rational expectations, as opposed to the case in which heuristics are used.

Having checked the model is determinate, the model under rational expectations is solved using the Binder and Pesaran procedure (1996). Otherwise, the behavioral rules set in Section 2 are employed when simulating the model with heuristics, and the model is solved iteratively (see Section 3.1).

Confirming standard results, we find that the model under rational expectations is unable to reproduce persistency of the time series, nor is it capable of matching the observed third and fourth moments in time series data. The rational expectations model is only capable of reproducing these features by slowing down the transmission of the shocks and that of the endogenous variables (by increasing the number of lags, i.e. relaxing the restrictions above on $b_{1}, c_{3}$ and $d_{1}+d_{2}$ ). Conversely, the model with heuristics replicates the stylized facts better both in terms of autocorrelation and non-normality, even when "mechanical frictions" are absent. 


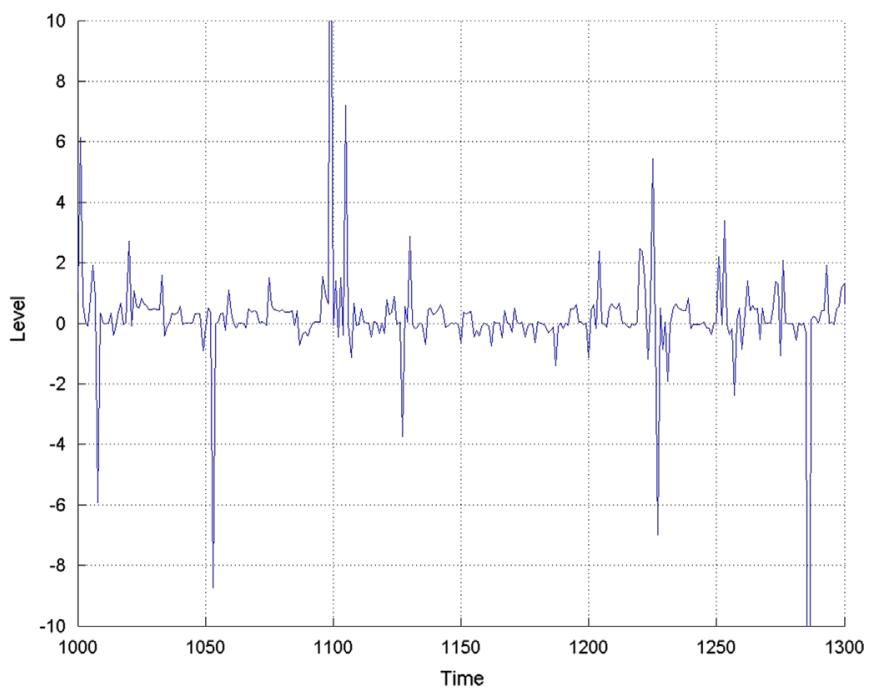

Fig. 16. Borrowing-lending spread.

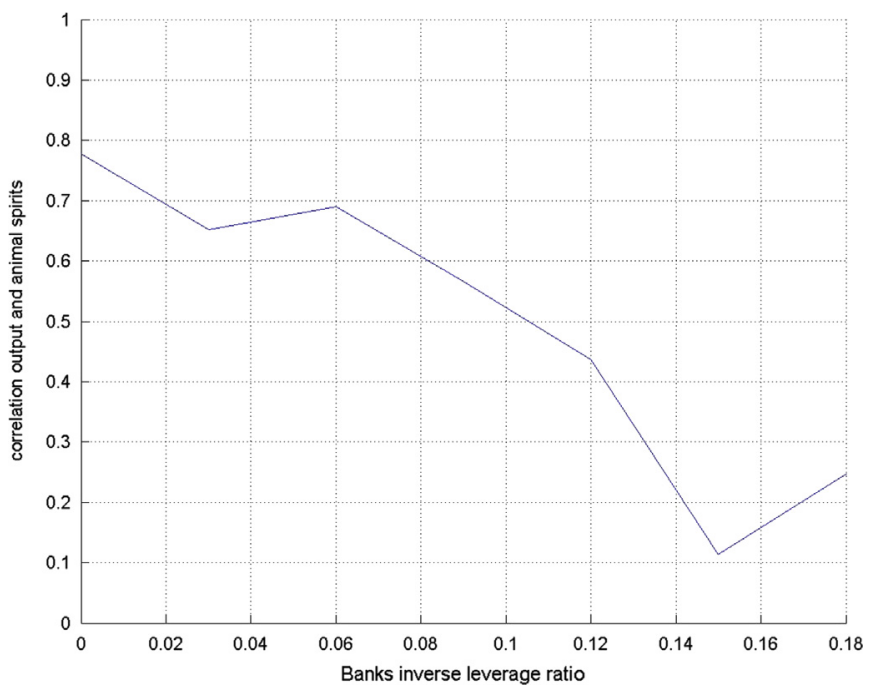

Fig. 17. Correlation output and animal spirits vs. banks' capital requirement.

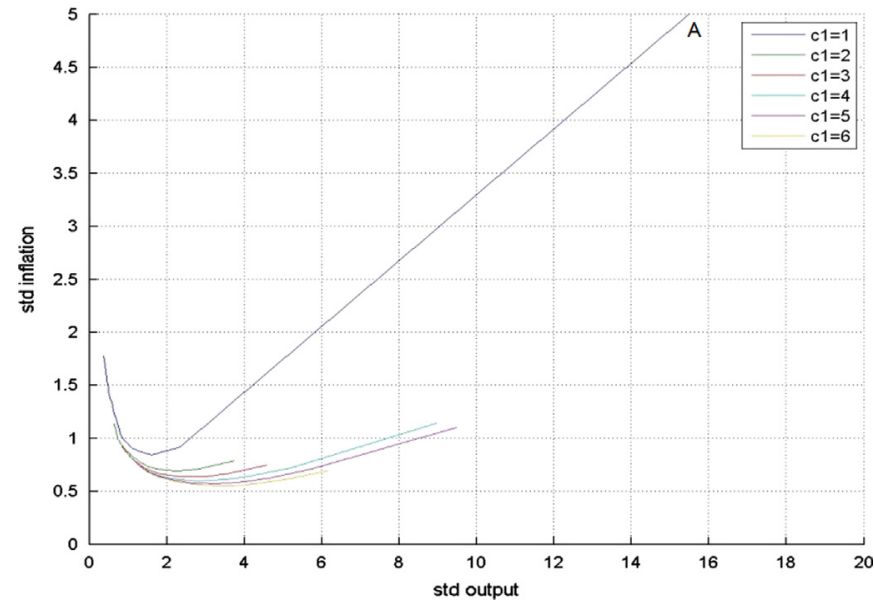

Fig. 18. Tradeoff output and inflation. 
Table 1

Model autocorrelations.

\begin{tabular}{llc}
\hline & Heuristics & $\begin{array}{c}\text { NK (Smets and } \\
\text { Wouters, 2003) }\end{array}$ \\
\hline No lags & & \\
Output gap & 0.77 & 0.07 \\
Inflation & 0.69 & -0.02 \\
& & \\
Inertia & & 0.79 \\
Output gap & 0.89 & 0.61 \\
Inflation & 0.90 & \\
\hline
\end{tabular}

Without any source of inertia in the model, the standard NK model under rational expectations produces a series for the output gap with very little or almost no autocorrelation (0.07) (see Table 1), and whose distribution is normal (kurtosis: 2.9, i.e. normality is non-rejected with $p$-value $=0.5$ based on the Jarque-Bera test). This is different from the model under heuristics where autocorrelated series and non-normality are attained, even though i.i.d. shocks are used and inertia terms are switched off. Looking at the top left section of Table 1, the output gap's autocorrelation of the model with heuristics and no lags is 0.77 . Normality is further rejected with $p$-value $=0.001$ (kurtosis is 5.9 ) based on the Jarque-Bera test. ${ }^{17}$

The possibility that imperfect information (departures from rational expectations) in NK models improves the empirical fit has also been documented by other recent contributions, including Collard and Dellas (2004, 2006) and Slobodyan and Wouters (2012). In particular, the latter consider learning in medium-scale DSGE models à la Smets and Wouters. They show that learning improves the fit of the model compared with the benchmark case of rational expectations. Along the same lines, Williams (2003), using simulation results, tests the effects of adaptive learning in benchmark RBC and New Keynesian models and compares the implied moments with those obtained under rational expectations. He shows that these effects are larger in the New Keynesian model compared to the standard RBC model. Finally, Jang and Sacht (2012), estimating De Grauwe's (2012) model using moment-based methods for the euro area data reach the same conclusions. In particular, the former authors confirm that a bounded rationality model with cognitive limitations provides a reasonable fit to auto and cross variance of the data series, compared to the model solution under rational expectations.

One may argue that the comparison of the behavioral model with the stylized version of the Smets and Wouters (2003) model is not complete. DSGE-models have been extended in several dimensions, being able to generate longer waves of booms and busts. While this is true, we show here that even a parsimonious model with heuristics can account for the intrinsic persistence in the data and for the non-normality in the movements of the output gap, a feature equally parsimonious models with rational expectations are unable to do.

Finally, one may ask why one should not take an "off the shelf" model with banking and simply introduce heuristics, so to as be able to compare the results under the rational expectation benchmark. First, it should be noted that our model is consistent with many reduced-form models available in the literature. ${ }^{18}$ In addition, taking an existing reduced-form DSGE model with banking and simply introducing heuristics would anyway imply expectation mechanisms to be imposed ex post on a reduced system of equations which themselves have been derived from maximizing behaviour under the assumption of rational expectations. This would have to be the case, unless axioms maintaining the rational expectation hypothesis at the aggregate level (e.g., Branch and McGough, 2009) are imposed. While we understand this represents an important venture for further research (and it is on our research agenda to investigate all such issues thoroughly), it goes beyond the scope of this article.

\section{Conclusion}

In this paper we have extended the behavioral macroeconomic model of De Grauwe (2012) to include a banking sector. The behavioral model takes the view that agents have limited congitive limitations. As a result, it is rational to use simple forecasting rules and to subject the use of these rules to a fitness test. Agents are then driven to select the rule that performs best. We believe that this is the proper way to define rationality in a world were agents do not understand the complexity of the world itself. It is also in this framework that the banking sector is introduced.

Our behavioral model produces endogenous and self-fulfilling movements of optimism and pessimism (animal spirits). Our main result is that the existence of banks intensifies these movements, creating a greater scope for booms and busts. Thus, banks do not create but amplify animal spirits. During booms, the equity of firms increases in value. This is a signal for the banks that the credit risk of firms declines. As a result, they are willing to lower the interest rate spread they charge on loans. The opposite occurs during a recession. Thus, credit works procyclically and intensifies the volatility of output. In the light of this we find that the equity ratio of banks can be used as a policy instrument, i.e. by raising the equity ratio of banks,

\footnotetext{
${ }^{17}$ The empirical autocorrelation of the US output gap is 0.96 (and kurtosis is 3.58) over the period 1960-2007.

${ }^{18}$ See also footnote number 9 .
} 
the amplification effect that is produced by the banking sector is reduced and and as a result the influence of animal spirits on economic activity is weakened, reducing the intensity of booms and busts in economic activity.

The other policy conclusion we derive from our results is that the central bank has an important responsibility for stabilising output. Output stabilization is an instrument to "tame the animal spirits". This has the effect of improving the tradeoff between inflation and output volatility.

\section{Acknowledgments}

The authors are grateful to participants at the Royal Economic Society meeting, the 2015 Agent-based Modeling for Economics and Finance workshop (Oxford), the 2014 Econometric Methods for Banking and Finance's Conference, the 20th International Conference on Computing in Economics and Finance, the 2014 Conference on Diversity in Macroeconomics (Essex), the CeNDEF-Conference in Amsterdam (2015) for constructive comments and discussions. The paper also benefited from comments provided by participants at one of the DED Seminar at the European Central Bank, a workshop on Behavioral Macroeconomis in Berlin (2014). The authors finally acknowledge comments from the Co-Editor and two anonymous referees.

\section{Appendix A}

See Figs. A1 and A2 and Table A1.

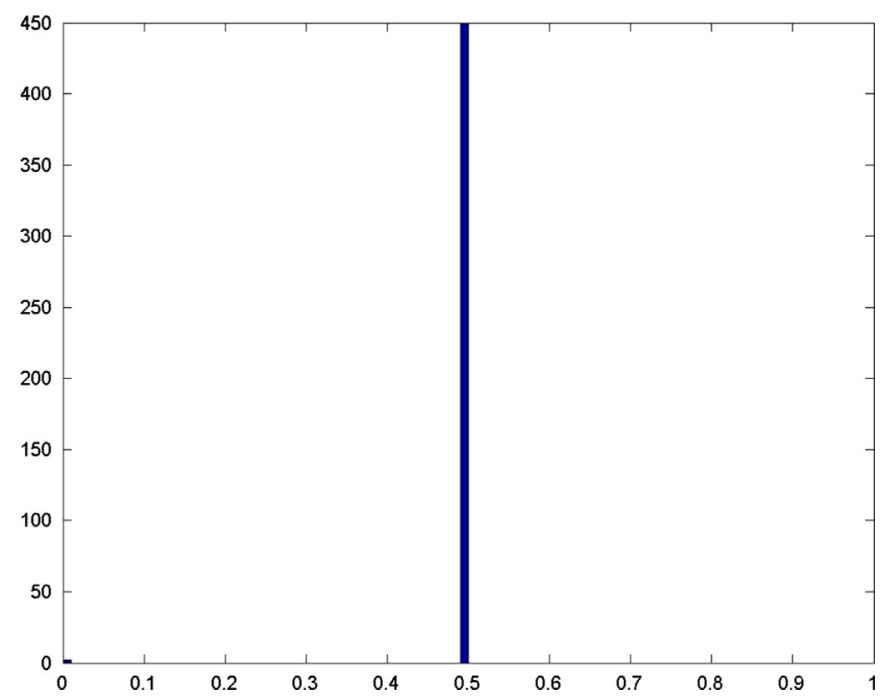

Fig. A1. Histogram animal spirits with agents tossing a coin. 


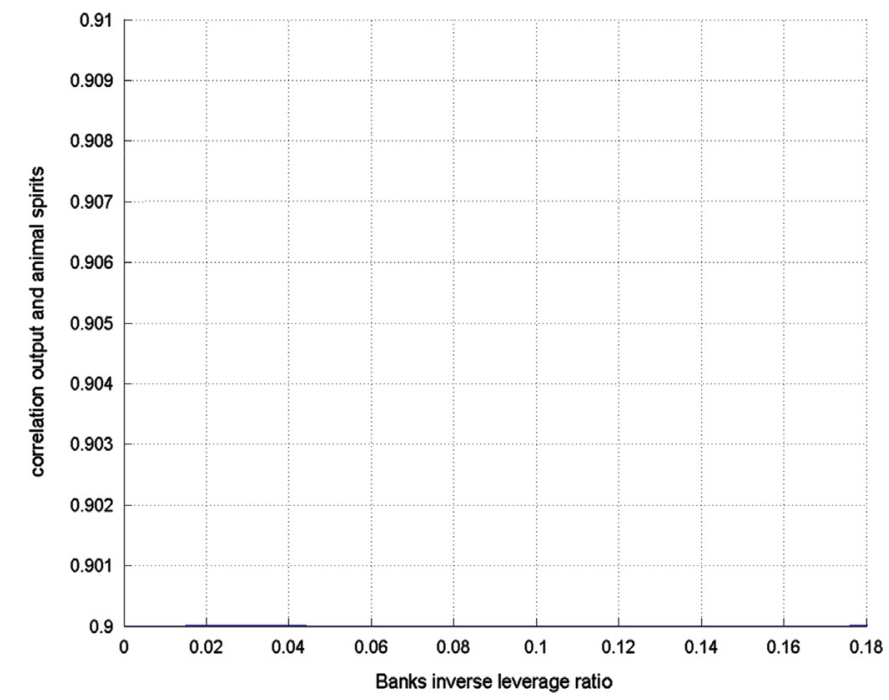

Fig. A2. Correlation output and animal spirits vs. banks' capital requirements with agents tossing a coin.

Table A1

Calibrated parameters in the model.

\begin{tabular}{|c|c|}
\hline $\begin{array}{l}\gamma=1.0 \\
\pi^{*}=0.0 \\
d_{1}=0.5 \\
e_{1}=0.1 \\
d_{2}=(0.5) *\left(1-d_{1}\right)-e_{1} \\
d_{3}=-0.01 \\
e_{2}=(-0.5) *\left(1-d_{1}\right)-d_{3}\end{array}$ & $\begin{array}{l}\text { switching parameter in Brock Hommes } \\
\text { the central bank's inflation target } \\
\text { marginal propensity of consumption out of income } \\
\text { coefficient on expected } y \text { in investment equation } \\
\text { coefficient on expected y in consumption equation to match } a_{1}=0.5 \\
\text { coefficient on real rate in consumption equation } \\
\text { coefficient on real rate in investment equation to match } a_{2}=-0.5\end{array}$ \\
\hline $\begin{array}{l}a_{1}=\left(e_{1}+d_{2}\right) /\left(1-d_{1}\right) \\
a_{1}^{\prime}=d_{2} /\left(1-d_{1}\right) \\
a_{2}=\left(d_{3}+e_{2}\right) /\left(1-d_{1}\right) \\
a_{3}=-d_{3} /\left(1-d_{1}\right)\end{array}$ & $\begin{array}{l}\text { coefficient of expected output in output equation } \\
\text { coefficient of lagged output in output equation } \\
\text { interest elasticity of output demand } \\
\text { coefficient on spread term in output equation }\end{array}$ \\
\hline $\begin{array}{l}b_{1}=0.5 \\
b_{2}=0.05 \\
c_{1}=1.5 \\
\varphi=-0.02 \\
\tau=1.43 \\
k=0.09\end{array}$ & $\begin{array}{l}\text { coefficient of expected inflation in inflation equation } \\
\text { coefficient of output in inflation equation } \\
\text { coefficient of inflation in Taylor equation } \\
\text { parameter on firm equity } \\
\text { firms' leverage (i.e. Pesaran and Xu (2013)) } \\
\text { banks' inverse leverage ratio (Gerali et al., 2010) }\end{array}$ \\
\hline $\begin{array}{l}e=0.05 \\
\alpha=0.2 \\
\bar{n}=40 \\
\bar{n}=60\end{array}$ & $\begin{array}{l}\text { equity premium } \\
\text { fraction of nominal GDP forecast in expected future dividends } \\
\text { number of shares in banks' balances sheets } \\
\text { initial value for number of firms' shares }\end{array}$ \\
\hline $\begin{array}{l}c_{2}=0.5 \\
c_{3}=0.5\end{array}$ & $\begin{array}{l}\text { coefficient of output in Taylor equation } \\
\text { interest smoothing parameter in Taylor equation }\end{array}$ \\
\hline $\begin{array}{l}\sigma_{1}=0.5 \\
\sigma_{2}=0.5 \\
\sigma_{3}=0.5\end{array}$ & $\begin{array}{l}\text { standard deviation shocks output equation } \\
\text { standard deviation shocks inflation equation } \\
\text { standard deviation shocks Taylor equation }\end{array}$ \\
\hline$p=0.5$ & speed of declining weights in mean squares errors (memory) \\
\hline
\end{tabular}

\section{References}

Adrian, T., Shin, H.S., 2010. Liquidity and leverage. J. Financ. Intermed. 19 (3), 418-437.

Anderson, S.P., De Palma, A., Thisse, J.F., 1992. Discrete Choice Theory of Product Differentiation. MIT Press13-62.

Ashraf, Q., Gershman, B., Howitt, P., 2011. Banks, Market Organization, and Macroeconomic Performance: An Agent-Based Computational Analysis, NBER Working Paper 17102.

Assenza, T., Heemeijer, P., Hommes, C., Massaro D., 2013. Individual Expectations and Aggregate Macro Behaviour, Tinbergen Institute Discussion Papers 13-016/II.

Ball, L., Mankiw, G., Reis, R., 2005. Monetary policy for inattentive economies. J. Monet. Econ. 52 (4), 703-725. 
Basel Committee on Banking Supervision, 2011. Basel III: A Global Regulatory Framework for More Resilient Banks and Banking Systems - Revised Version June, Bank for International Settlements, 92-9197-859-0.

Bernanke, B.S., Gertler, M., 2001. Should central banks respond to movements in asset prices? Am. Econ. Rev. 91 (2), $253-257$.

Bernanke, B.S., Gertler, M., Gilchrist, S., 1999. The financial accelerator in a quantitative business cycle framework. In: Taylor, J.B., Woodford, M. (Eds.), , North-Holland, Amsterdam.

Bernanke, B.S., Blinder, A.S., 1988. Credit, money, and aggregate demand. Am. Econ. Rev. 78 (2), 435-439.

Binder, M., Pesaran, M.H., 1996. Multivariate rational expectations models and macroeconomic modelling: a review and some results. In: Pesaran, M.H. Wickens, M. (Eds.), Handbook of Applied Econometrics: Volume I Macroeconomics, pp. 139-187.

Blanchard, O.J., Kahn, C.M., 1980. The solution of linear difference models under rational expectations. Econometrica 48 (5), $1305-1311$.

Bloomfield, R., Hales, J., 2002. Predicting the Next Step of a Random Walk: Experimental Evidence of Regime-Shifting Beliefs. Journal of Financial Economics 65 (3), 397-414.

Branch, W.A., McGough, B., 2009. A new Keynesian model with heterogeneous expectations. J. Econ. Dyn. Control 33 (5), $1036-1051$.

Branch, W., Evans, G., 2007. Model uncertainty and endogenous volatility. Rev. Econ. Dyn. 10 (2), $207-237$.

Branch, W.A., 2002. Local convergence properties of a Cobweb model with rationally heterogeneous expectations. J. Econ. Dyn. Control 27 (1), 64-85.

Branch, W.A., 2004. The theory of rationally heterogeneous expectations: evidence from survey data on inflation expectations. Econ. J. 114 (497), $592-621$.

Branch, W.A., 2007. Sticksy information and model uncertainty in survey data on inflation expectations. J. Econ. Dyn. Control 31 (1), $245-276$.

Brealey, R.A., Myers, S.C., 1984. Principles of Corporate Finance, 2nd edition McGraw-Hill, New York.

Brock, W.A., Hommes, C.H., 1997. A rational route to randomness. Econometrica 65 (5), 1059-1096.

Brock, W.A., Hommes, C.H., 1998. Heterogeneous beliefs and routes to chaos in a simple asset pricing model. J. Econ. Dyn. Control 22 (8-9), 1235-1274.

Brunnermeier, M., Pedersen, L., 2009. Market Liquidity and Funding Liquidity. Rev. Financ. Stud. 22 (6), $2201-2238$.

Campbell, J.Y., Shiller, R.J., 1987. Cointegration and tests of present value models. J. Polit. Econ. 95 (5), $1062-1088$.

Carroll, C.D., 2003. Macroeconomic expectations of households and professional forecasters. Q. J. Econ. 118 (1), $269-298$.

Carroll, C.D., 2012. Implications of Wealth Heterogeneity For Macroeconomics, Presentation to Federal Reserve Board, May 14

Castle, J.L., Doornik, J.A., Hendry, D., 2010. Testing the Invariance of Expectations Models of Inflation, Economics Series Working Papers 510, University of Oxford, Department of Economics.

Case, K.E., Quigley, J.M., Shiller, R.J., 2003. Comparing Wealth Effects: The Stock Market Versus the Housing Market, Institute of Business and Economic Research Working Paper W01-004.

Clarida, R., Gali, J., Gertler, M., 1999. The science of monetary policy: a new Keynesian perspective. J. Econ. Lit. 37 (2), $1661-1707$.

Collard, F., Dellas, H., 2004. The New Keynesian Model with Imperfect Information and Learning, Mimeo, CNRS-GREMAQ.

Cogley, T., 2002. A simple adaptive measure of core inflation. J. Money Credit Bank. 34 (1), 94-113.

Cogley, T., Sargent, T., 2007. Inflation-Gap Persistence in the US, Mimeo. Northwestern University.

Collard, F., Dellas, H., 2006. Misperceived Money and Inflation Dynamics, Mimeo, CNRS-GREMAQ

Cornea, A., Hommes, C.H., Massaro, D, 2012. Behavioural Heterogeneity in U.S. Inflation Dynamics, CeNDEF Working Papers 12-03.

Curdia, V., Woodford, M., 2010. Credit spreads and monetary policy. J. Money Credit Bank. 42 (1), 3-35.

De Grauwe, P., 2008a. Stock Prices and Monetary Policy, CEPS Working Document No. 304, September.

De Grauwe, P., 2008b. DSGE-Modelling when Agents are Imperfectly Informed. ECB Working Paper 897.

De Grauwe, P., 2011. Animal spirits and monetary policy. Econ. Theory 47 (2-3), 423-457.

De Grauwe, P., 2012. Lectures on Behavioral Macroeconomics. Princeton University Press.

Delli Gatti, D., Gallegatti, M., Greenwald, B.C., Russo, A., Stiglitz, J.E., 2008. Financially Constrained Fluctuations in an Evolving Network Economy, NBER Working Paper 14112.

European Central Bank, 2011. The Monetary Policy of the ECB. ECB.

Evans, G., Honkapohja, S., 2001. Learning and Expectations in Macroeconomics. Princeton University Press45-58.

Evans, G., Honkapohja, S., Romer, P., 1998. Growth cycles. Am. Econ. Rev. 88 (3), 495-515.

Evans, G.W., McGough, B., 2005. Monetary policy, indeterminacy and learning. J. Econ. Dyn. Control 29 (11), $1809-1840$.

Frankel, J., Froot, K., 1987. Using survey data to test standard propositions regarding exchange rate expectations. Am. Econ. Rev. 77 (1), 133-153.

Frankel, J., Froot, K., 1990. Chartists, fundamentalists, and trading in the foreign exchange market. Am. Econ. Rev. 80 (2), $181-185$.

Friedman, M.A., 1963, Windfalls, the 'Horizon,' and Related Concepts in the Permanent Income Hypothesis," in Measurement in Economics, ed. by Carl Christ, et al., pp. 1-28. Stanford University Press.

Fuhrer, J., Moore, G., 1995. Inflation persistence. Q. J. Econ. 110 (1), 127-159.

Gali, J., Gertler, M., 1999. Inflation dynamics: a structural econometric approach. J. Monet. Econ. 44 (2), $195-222$.

Geanakoplos, J., 1997. Promises, Promises. In: System II, W., Brian Arthur, S., Durlauf, Lane, D. (Eds.), , Addison-Wesley, Reading, MA, pp. 285-320.

Geanakoplos, J., 2009. The Leverage Cycle. Cowles Foundation Discussion Papers 1715, Cowles Foundation for Research in Economics, Yale University.

Gerali, A., et al., 2010. Credit and banking in a DSGE model of the Euro area. J. Money Credit Bank. 42 (1), 107-141.

Harvey, A.C., Jaeger, A., 1993. Detrending, stylised facts and the business cycle. J. Appl. Econom. 8, $231-247$.

Hendry, D., Mizon E.G., 2010. On the Mathematical Basis of Inter-temporal Optimization, Department of Economics Discussion Paper series 497, University of Oxford.

Hommes, C., 2011. The heterogeneous expectations hypothesis: some evidence from the lab. J. Econ. Dyn. Control 35 (1), $1-24$.

Hommes, C., Sonnemans, J., Tuinstra, J., van de Velden, H., 2005. Coordination of expectations in asset pricing experiments. Rev. Financ. Stud. 18 (3), 955-980.

Honkapohja, S., Mitra, K., 2005. Performance of monetary policy with internal central bank forecasting. J. Econ. Dyn. Control 29 (4), $627-658$.

Howitt, P., McAfee, R.P., 1992. Animal spirits. Am. Econ. Rev. 82 (3), 493-507.

Iacoviello, M., Neri, S., 2010. Housing market spillovers: evidence from an estimated DSGE model. Am. Econ. J.: Macroecon. 2 (2), 125-164.

Jang, T.-S., Sacht, S., 2012. Identification of Animal Spirits in a Bounded Rationality Model: An Application to the Euro Area, Economics Working Papers 12 , Christian-Albrechts-University of Kiel.

Levine, P., Pearlman, J., Perendia, G., Yang, B., 2012. Endogenous persistence in an estimated DSGE model under imperfect information. Econ. J. 122 (565), $1287-1312$

Mackowiak, B., Wiederholt, M., 2005. Optimal Sticky Prices Under Rational Inattention, Discussion Paper. Humboldt University, Berlin.

Mankiw, N.G., Ball, L., 2010. Macroeconomics and the Financial System. Worth Publishers (Chapter 19).

Mankiw, N.G., Reis, R., 2002. Sticky information versus sticky prices: a proposal to replace the new Keynesian Phillips curve. Q. J. Econ. 117 (4), 1295-1328.

Mankiw, NG.., Reis, R., 2007. Sticky information in general equilibrium. J. Eur. Econ. Assoc. 5 (2-3), $603-613$.

Mankiw, N.G., Reis, R., Wolfers, J., 2004. Disagreement About Inflation Expectations, NBER Macroeconomics Annual 2003 , vol. 18, pp. 209-270.

Manski, C.F., McFadden, D.L., 1981. Alternative estimators and sample designs for discrete choice analysis. In: Manski, C.F., McFadden, D.L. (Eds.), , The MIT Press, Cambridge.

Massaro, D., 2013. Heterogeneous expectations in monetary DSGE models. J. Econ. Dyn. Control 37 (3), $680-692$.

Mehra, R., Piguillem, F., Prescott E.C., 2008. Intermediated Quantities and Returns, Research Department, Staff Report 405, Federal Reserve Bank of Minneapolis.

Milani, F., 2007. Expectations, learning and macroeconomic persistence. J. Monet. Econ. 54 (7), $2065-2082$.

Williams, N., 2003. Adaptive Learning and Business Cycles, Mimeo. University of Wisconsin, Social Science Computing Cooperative. 
Milani, F., 2012. The Modelling of Expectations in Empirical DSGE Models: A Survey, University of California-Irvine, Department of Economics Working Papers 121301.

Pesaran, H.M., 1987. The Limits of Rational Expectations. Blackwell Publishing.

Pesaran, M.H., Xu, T., 2013. Business Cycle Effects of Credit Shocks in a DSGE Model with Firm Defaults, Working Papers 13-19, Bank of Canada.

Pfajfar, D., Zakelj, B., 2011. Inflation Expectations and Monetary Policy Design: Evidence from the Laboratory (Replaces CentER DP 2009-007), Discussion Paper 2011-091, Tilburg University, Center for Economic Research.

Pfajfar, D., Santoro, E., 2010. Heterogeneity, learning and information stickiness in inflation expectations. J. Econ. Behav. Organ. 75 (3), $426-444$.

Reis, R., 2009. Optimal monetary policy rules in an estimated sticky-information model. Am. Econ. J.: Macroecon. 1 (2), $1-28$.

Roos, M.W.M., Schmidt, U., 2012. The importance of time-series extrapolation for macroeconomic expectations. Ger. Econ. Rev. 13 (2), 196-210.

Sargent, T.J., 1994. Bounded Rationality in Macroeconomics: The Arne Ryde Memorial Lectures. Oxford University Press.

Schorfheide, F., 2005. Learning and monetary policy shifts. Rev. Econ. Dyn. 8 (2), 392-419.

Sims, C.A., 2003. Implications of rational inattention. J. Monet. Econ. 50 (3), 665-690.

Sims, C.A., 2005. Rational Inattention: A Research Agenda, Discussion Paper 34, Deutsche Bundesbank.

Slobodyan, S., Wouters, R., 2012. Learning in a medium-scale DSGE model with expectations based on small forecasting models. Am. Econ. J.: Macroecon. 4 (2), 65-101.

Smets, F., Wouters, R., 2003. An Estimated dynamic stochastic general equilibrium model of the euro area. J. Eur. Econ. Assoc. 1 (5), $1123-1175$.

Smets, F., Wouters, R., 2007. Shocks and frictions in US business cycles: A bayesian DSGE approach. Am. Econ. Rev. 97 (3), $586-606$.

Trabandt, M., 2007. Sticky Information vs. Sticky Prices: A Horse Race in a DSGE Framework, Kiel Institute for the World Economy Working Paper 1369.

Woodford, M., 2003. Interest and Prices: Foundations of a Theory of Monetary Policy. Princeton University Press. 